\title{
Análisis del Sistema Monetario Internacional *
}

BREVE HISTORIA

En la conferencia de Génova de 1922 se acordó establecer un sistema monetario internacional basado en un "patrón oro-cambio", a través del cual los paises que se acogieron al mismo, podían mantener sus reservas internacionales en oro o en divisas convertibles en oro.

Una de las divisas que garantizaba su convertibilidad en oro exa la libra esterlina, divisa que fue atacada fuertemente en 1931, cuando Francia exigió a Inglaterra la conversión de parte de sus reservas de libras en oro; reservas que habian tomado magnitudes de consideración debido al superávit que en los años anteriores había gozado Francia como consecuencia de la subvaluación del franco en el mercado internacional.

Esta exigencia de conversión, así como los efectos de la depresión de los años 30 , originaron la aparición de serios déficits en la balanza de pagos británica, hecho que impulsó a este país a declarar la inconvertibilidad de su moneda en oro.

Por otra parte, siendo obligatorio para los bancos centrales mantener sus reservas en oro $\mathrm{y} / \mathrm{o}$ en moneda convertible, se originó un proceso de sustitución de divisas por oro, incluyéndose en este proceso al dólar norteamericano.

Esta creciente demanda por el metal aurífero se vio acentuada como consecuencia del proceso de recesión mundial de los años 30 , que dio origen a sucesivas devaluaciones de diversas monedas, introduciéndose así frecuentes incertidumbres con referencia al valor de las divisas atesoradas en forma de reservas. Esto dio lugar a preferencias cada vez mayores por el oro, en detrimento de las monedas convertibles.

*El autor agradece a los señores Lawrence R. Klain, Gustavo Lagos y Carlus Rafael Silva, por los útiles y acertados comentarios que hicieran al manuscrito de este trabajo. 
LOS ACUERDOS DE BRETTON WOODS ${ }^{1}$

Al perfilarse el triunfo aliado en la Segunda Guerra Mundial, se convocó a una reunión a celebrarse en 1944 en la ciudad de Bretton Woods, N. H., E. U. A., con el fin de discutir y estructurar el nuevo sistema monetario de la postguerra.

Fue en esa conferencia donde se elaboró el "Tratado de Bretton Woods", el cual recogía las bases sobre las que se edificaría el sistema monetario internacional, que imperaría en el mundo occidental por casi tres décadas. Grosso modo, el sistema ideado reafirmaba el "Patrón oro-cambio" de la preguerra, pero estableciendo una serie de normas y principios que impedirían la repetición de los hechos que se vivieron en los años 30 y que motivaron el fracaso del Sistema establecido en Grénova en 1922.

La decisión de regirse por un patrón "oro-cambio" se debía al hecho de que, bajo dicho patrón, las posibilidades de expansión de la liquidez internacional, atendiendo las necesidades que de éste se tuvieran, serían mucho mayores que bajo un sistema de "patrón oro", por ejemplo, ya que en el primero, las reservas internacionales de los países, podían estar formadas no sólo por oro, -cuya producción era inelástica-, sino también, por divisas convertidas en oro.

El dólar, que pasaba a ser la moneda internacional, era plenamente convertible a un precio fijo de $\$ 35$ por onza troy, a la vez que el resto de las monedas debían establecer su valor en términos de oro, o lo que es lo mismo, en forma indirecta, establecerse una paridad "fija" respecto al dólar, estando obligados los gobiernos a intervenir en el mercado, para asegurar el cumplimiento de este compromiso. En otras palabras, se instauró un sistema de "cambios fijos".

Tan sólo en casos extremos, -como desequilibrios crónicos en la balanza de pagos-, los gobiernos podrían fluctuar este tipo de cambio previamente establecido.

Sin embargo, dados los múltiples y amargos ejemplos de la inoperabilidad del Sistema en la preguerra, se acordó que era indispensable la creación de un organismo que velara por el cumplimiento de las normas sobre las que se basarían las nuevas relaciones financieras internacionales. Dicho organismo fue el Fondo Monetario Internacional.

1 Para mayor información ver Friedman (27), Grubel (33), Klopstock (46), Snider (82), Triffin (87). 
EL FONDO MONETARIO INTERNACIONAL ${ }^{2}$

Todo país que manifestara deseo de integrarse en el Fondo gozaba del derecho de hacerlo, pero, automáticamente, se comprometia a obedecer las "reglas del juego", estipuladas por este organismo.

Todo país, al unirse al Fondo, debía pagar una cuota estipulada por este último, la cual determinaría el poder de voto del país, así como su capacidad de crédito a través de los Derechos de Giro, que serán explicados más adelante.

La determinación de la cuota fue objeto de debate en la conferencia de Bretton Woods, ya que había dos proposiciones para el establecimiento de ésta, a saber, la posición norteamericana, expuesta por H. White, y la posición británica, presentada por John M. Keynes. ${ }^{3}$

El plan White sostenía, que el cálculo de la cuota debia hacerse de acuerdo a la posesión de oro de cada país, su ingreso nacional y su escala de pagos internacionales. Por el contrario, el plan Keynes proponía, que dicha cuota se estableciera sobre la base de los niveles de exportaciones e importaciones de cada país, durante los tres últimos años que precedieron a la Segunda Guerra. Como era de esperar, cada uno de estos planes favorecía notoriamente al pais que los presentaba. Finalmente prevaleció el criterio norteamericano, permitiendo que los E. U. A. tuvieran la mayor cuota en el Fondo $(\$ 2.750$ millones), seguido por la Gran Bretaña, con $\$ 1.300$ millones. Esto significó que los E. U. A. tenían el $31,25 \%$ de la cuota total, y por consiguiente, el correspondiente porcentaje de los votos del Fondo. Es obvia la posición de líder que tomó este país desde un principio, entre las 45 naciones que suscribieron el Convenio en 1946 y entre los cuales se encontraba la Unión Soviética, que se retiraría poco después. Las cuotas han sido modificadas varias veces desde 1946, hasta el presente (1975), habiendo sido de especial importancia para los países productores de petróleo, la revisión realizada a comienzos de 1975, ya que, en esta oportunidad, se duplicaron las cuotas de estos páses, confiriéndoles un poder de voto considerablemente mayor.

Cada país debía depositar su cuota en el Fondo, y la misma estar compuesta por un $25 \%$ en oro y el $75 \%$ restante, en moneda nacional.

${ }^{2}$ Ver Fleming (22) .

'Ver Grubel (33). 
Dado que la estabilidad del tipo de cambio, es uno de los pilares en que se basaba el Sistema Monetario de Bretton Woods, se hacia necesario la creación de un mecanismo que, manejado por el Fondo Monetario Internacional, asegurara esa estabilidad entre aquellos miembros cuyas reservas internacionales no fueran suficientes para respaldar y mantener la paridad de sus monedas. Ese mecanismo fue el de los "Derechos de Giro"', que no son sino préstamos de divisas a corto plazo. El país que hace uso de esos "Derechos de Giro", solicita del Fondo un determinado monto de divisas extranjeras de acuerdo a sus necesidades, cancelándolas al Fondo en moneda nacional, pero comprometiéndose a que, al finalizar el plazo del préstamo, el país prestatario recomprará su moneda nacional, pagando la misma con divisas de las adquiridas en el préstamo.

Un ejemplo clarificará el proceso:

Supóngase un país " $\mathrm{X}$ ", cuya moneda nacional es el "peso", y su tipo de cambio sea de 5 pesos por dólar. Si dicho país solicita del Fondo en préstamo $\$ 1$ millón a través del mecanismo de Derechos de Giro, este país entregará de inmediato 5 millones de "pesos" a cambio del millón de dólares. Al vencimiento del préstamo, el país " $\mathrm{X}$ " tendrá que recomprar los 5 millones de pesos, dando al Fondo un millón de dólares.

Se estableció un límite máximo de crédito para cada miembro, de tal forma que, en ningún momento, el Fondo podía mantener en moneda nacional de cualquier país, un monto mayor al $200 \%$ de su cuota. Dado que el F. M. I. dispone del $75 \%$ de la cuota de cada país en su respectiva moneda nacional, ningún miembro podría solicitar un préstamo a través del mecanismo de "Derechos de Giro" que excediera del $125 \%$ de su cuota. Acudiendo de nuevo a nuestro ejemplo, si la cuota del país " $X$ " es de $\$ 2$ millones, o sea, un equivalente a 10 millones de pesos, el $75 \%$ de dicha cuota estaría constituida en pesos; y el límite máximo de préstamo sería de 20 millones de pesos (200\% de la cuota), o sea $\$ 4$ millones. En vista de que el Fondo ya tiene 7,5 millones de pesos ( $75 \%$ de 10 millones de pesos), en su poder, el máximo que puede ser solicitado en préstamo por el país " $X$ " es 12,5 millones de pesos $(20-7,5=12,5)$, cantidad que representa el $125 \%$ de la cuota de 10 millones.

Estos límites fueron posteriormente ampliados para los países en vías de desarrollo hasta un $225 \%$, lo que equivale a un máximo de crédito efectivo del $150 \%$ de la cuota.

Todo miembro tiene derecho adquirido a obtener un préstamo en forma automática por un monto hasta del $25 \%$ de su cuota. Si desea un préstamo mayor, el Fondo podría imponer condiciones al país

"No debe confundirse con los "Derechos Especiales de Giro" o D.E.G. 
solicitante, tales como la aplicación de ciertas medidas económicas y otras semejantes. Esta característica da pie, sin embargo, a que los países que "dominan" el F. M. I., por su elevado poder de voto, puedan actuar contra los intereses de países más débiles, al serles negado un préstamo, debido a influencias o decisiones de aquellos, de diversa índole.

Estos actos discriminatorios, no habrían sucedido de haberse aprobaclo el plan de Keynes, según el cual, los Derechos de Giro eran una especie de depósito que cada país poseía en forma automática y contra el que podrían girar cuando así lo juzgaran conveniente. De esta forma, el país disminuiría su Derecho de Giro, en un equivalente al uso que éste hiciera de ese "depósito", para adquirir una divisa específica, mientras que el país emisor de dicha divisa, aumentaría su Derecho de Giro en esa misma cantidad.

EL PAPEL DEL DÓLAR EN EL NUEVO SISTEMA ${ }^{5}$

De las conversaciones de Bretton Woods se concluyó que el dólar, y en menor grado, la libra esterlina, podrían servir de moneda de reserva a escala internacional.

Al establecerse la convertibilidad del dólar en oro a razón de $\$ 35$ la onza troy, se le dio a esa moneda una aceptabilidad mundial, ya que la misma era tan buena como el oro, o quizás mejor, pues sus poseedores podrían obtener intereses.

Este hecho era de particular trascendencia para la época, pues no disponiendo los países europeos de los recursos necesarios para realizar las operaciones de reconstrucción de la postguerra, los E. U. A., -que para la fecha disponían de gran cantidad de reservas-, se com. prometieron a suplir esos recursos a los países europeos.

Fue así como se comenzó a operar el flujo de dólares al viejo continente en forma cle subsidios y préstamos a través del plan Marshall, flujo que permitió a estos países iniciar el rápido proceso de reconstrucción. Esto dio origen a la aparición de déficits en la balanza de pagos norteamericana y saldos activos en las de los países europeos.

En otras palabras, los E. U. A., quienes habían pasado a ser los "banqueros del mundo", estaban aumentando sus deudas líquidas externas, para con los países receptores de estos dólares.

Sin embargo, estos últimos, pasados unos años, estaban dispuestos

"Ver Grubel (33), Kindleberger (45) y Machlup (52). 
a aceptar estos dólares, que constitúan el pasivo norteamericano, pues los mismos podían ser convertibles en oro en cualquier momento, convertibilidad que quedaba asegurada porque los Estados Unidos tenían reservas internacionales con un monto mucho mayor que sus deudas líquidas externas.

Esta situación se mantuvo más o menos estable hasta fines de la década de los 50, pues, a pesar de que la cantidad de dólares en poder de los paises europeos iba en aumento, la relación de reservas internacionales con respecto a la deuda líquida externa, era mayor que la unidad (ver tabla No 1), por lo cual, los países europeos, no tenían por qué temer que en un momento dado los Estados Unidos no tuviesen con qué respaldar la promesa de convertibilidad automática del dólar.

Sin embargo, a partir de 1958, la salida de capitales de los Estados Unidos, comenzó a aumentar considerablemente, como consecuencia de los crecientes gastos militares en el exterior, los préstamos y ayudas a otros palses, las inversiones en acciones de compañfas extranjeras y las transferencias privadas de capital, atraldas por los mayores intereses ofrecidos a éstos en otros lugares del globo. Por otra parte, durante estos años que siguieron a la crisis de Suez, los países del mundo occidental, pesimistas por las incertidumbres de futuros suministros de petróleo, de los cuales dependían en gran medida, así como de las posibilidades de aumentos bruscos en los precios del crudo y sus derivados, decidieron fortalecer sus reservas internacionales para así poder hacer frente a cualquier eventualidad adversa. Esto acarreó que el déficit de la balanza de pagos norteamericana se incrementara, y que por tanto, la tenencia de dólares en los países europeos fuera en constante aumento, estimulando a estos últimos países a incrementar la conversión de parte de los dólares que poselan, por oro norteamericano. En 1960 se observó, por primera vez, que el monto de estas reservas era inferior a la deuda líquida externa, ya que la relación entre ambas magnitudes era de 0,92 cuando en 1950, la misma era de 2,73. Dicha tendencia desfavorable siguió operándose en la década de los 60, llegando en 1967 a tan sólo 0,45.

Tal hecho originó la desconfianza, cada vez mayor, de los passes tenedores de dólares, en la capacidad de los E. U. A. para mantener su compromiso de convertibilidad, por lo que los cambios de dólares por oro, se hacían cada vez más frecuentes y mayores, conduciendo a la merma de reservas de ese metal en poder de los E. U. A.

Otro factor que contribuyó a la reducción de las reservas de oro norteamericanas, fue el empeño de este pais y de otros europeos, en mantener el precio de ese metal en el mercado libre, al mismo nivel de $\$ 35$ la onza troy. Para ello se creó un "pool del oro", que tenía como objetivo aumentar las ventas de ese metal en el mercado 
cuando aparecieran tendencias alcistas en sus precios, con el fin de reducir los precios a través de la ley de la oferta y la demanda, a los niveles deseados. Estas actividades finalizaron bruscamente el mes de marzo de 1968, cuando, dadas las considerables mermas en las reservas de oro norteamericanas, y la creciente demanda del metal para fines industriales, se decidió separar ambos mercados.

\section{TABLA NQ I}

RESERVAS INTERNACIONALES Y PASIVOS Ĺ́QUIDOS EXTTRNOS DE LOS ESTADOS UNIDOS (Miles de millones de $\$$ )

\begin{tabular}{|c|c|c|c|}
\hline & Reservas Internacionales & $\begin{array}{c}(2) \\
\text { Pasivos } \\
\text { Liquidos Exiernos }\end{array}$ & $\frac{(1)^{(3)}}{(2} \cdot 100$ \\
\hline 1950 & 24,3 & 8,9 & 2,79 \\
\hline 1951 & 24,3 & 8,9 & 2,73 \\
\hline 1952 & 24,7 & 10,4 & 2,38 \\
\hline 1958 & 28,5 & 11,4 & 2,06 \\
\hline 1954 & 23,0 & 12,5 & 1,84 \\
\hline 1955 & 22,8 & 13,5 & 1,69 \\
\hline 1956 & 23,7 & 14,9 & 1,59 \\
\hline 1957 & 24,8 & 15.8 & 1,57 \\
\hline 1958 & 22,5 & 16,8 & 1,34 \\
\hline 1959 & 21,5 & 19,4 & 1,11 \\
\hline 1960 & 19,4 & 21,0 & 0,92 \\
\hline 1961 & 18,8 & 22,9 & 0,82 \\
\hline 1962 & 17,2 & 24,1 & 0,71 \\
\hline 1963 & 16,8 & 26,3 & 0,64 \\
\hline 1964 & 16,7 & 29,0 & 0,58 \\
\hline 1965 & 15,5 & 29,1 & 0,53 \\
\hline 1966 & 14,9 & 29,8 & 0,50 \\
\hline 1967 & 14,8 & 38,2 & 0,45 \\
\hline 1968 & 15,7 & 33,6 & 0,47 \\
\hline 1969 & 17,0 & 41,9 & 0,41 \\
\hline 1970 & 14,5 & 43,2 & 0,84 \\
\hline 1971 & 13,2 & 64,2 & 0,21 \\
\hline
\end{tabular}

FUENTE: Grubel, H. G., "The International Monetary System", Penguin, 1968, pág. 138.

I. M.F., "International Financial Statistics", abril 1972, pág. 367. 
ESTADOS UNIDOS COMO BANQUERO MUNDIAL ${ }^{B}$

La posición de líder de los E. U. A. en el Sistema Monetario Internacional, le daba a dicho país una serie de ventajas. En primer lugar, no tenía necesidad de guardar celosamente las divisas que formaban parte de sus reservas internacionales, como lo tenía que hacer cualquier otro país, pues eran ellos los que "producían" dichas divisas.

En efecto, para cualquier nación sería imposible mantener déficits en su balanza de pagos en forma indefinida y con magnitudes de gran volumen, como lo han hecho los E. U. A., pues ello significaría el agotamiento rápido de sus reservas internacionales. Sin embargo, si bien el déficit estadounidense en su balanza de pagos, ha sido una de las causas indirectas de la merma considerable de sus reservas internacionales, que en su gran mayoría han estado formadas por oro, dicho déficit se ha originado, por el exceso de dólares emitidos y lanzados al mundo por ese país.

En segundo lugar, este exceso de dólares emitidos permitió a los E. U. A., realizar inversiones cuantiosas en el exterior, creando industrias de gran magnitud en Europa y otras partes del globo, así como adquiriendo o controlando otras ya existentes.

Igualmente, le fue posible financiar programas de ayudas, tanto militares como civiles. En otras palabras, sólo le bastaba poner a funcionar la impresora de billetes y lanzar éstos al mundo.

Sin embargo, en los años 60, los niveles de déficit acumulados en su Cuenta Capital eran ya de gran magnitud. Los E. U. A. vieron la necesidad de afrontar el problema y tomar acciones para corregirlo. Con todo, dacla su condición de líder, a este país no le era tan fácil aplicar las medidas que cualquier otra nación habría tomado ante situaciones semejantes, como serían, la devaluación de su moneda, la restricción y selección de sus importaciones, el control de cambios y otras similares. Ante tal situación, la única alternativa consistía, en mantener los precios a niveles inferiores a los de sus competidores, o al menos, que los mismos crecieran a un ritmo menor que los precios de aquellos. De esta forma se desestimularían las importaciones y se estimularían las exportaciones, fortaleciendo así el superávit de la balanza de pagos en Cuenta Corriente, lo que permitiría en cierta medida, compensar parcialmente el déficit de la Cuenta Capital.

'Para mayor detalle ver Grubel (32), Roosa (69), Triffin (86). 
La anotada política deflacionista de los precios traía, sin embargo, sus problemas, pues estimulaba la recesión económica con el consiguiente aumento del desempleo. También se puso en práctica un programa para que, voluntariamente, los norteamericanos restringieran la salida de capitales al exterior y los bancos de ese país redujeran sus empréstitos a otros países.

Como veremos más adelante, estas medidas fueron insuficientes para controlar la situación de déficit, ya que el dólar estaba considerablemente sobrevaluado respecto a las monedas de los países competidores en el mercado internacional, tales como Japón, Alemania, Francia y otros, situación esta que obligó a los E. U. A. a la devaluación de facto de su signo monetario, a mediados de 1971 .

Durante los años 60, los países europeos, receptores de cantidades de cada vez mayores de dólares, instaban a los E. U. A. a tomar medidas más drásticas, para controlar la salida de esta divisa hacia sus países, ya que, ni Japón, ni los miembros del Mercado Común Europeo, estaban dispuestos a tomar acciones tendientes a restringix la entrada de esos dólares. En otras palabras, estos países no deseaban, bajo ninguna circunstancia, revaluar sus monedas, para así reducir los crecientes superavits de sus balanzas de pagos, y, por ende, para evitar la entrada de más dólares a sus saturadas bóvedas, ya que esa medida, restringiría sus exportaciones, originando contracciones internas en sus economías. Por otra parte, las revaluaciones de estas monedas, no significarían otra cosa, que darle ventaja a los competidores norteamericanos en el mercado internacional, en detrimento de sus propias industrias.

Una consecuencia del flujo de dólares al exterior de los E. U. A., fue la formación del llamado mercado de "eurodólares" que se vio fortalecido, aun cuando parezca antagónico, por todas las medidas restrictivas de salidas de capital implantadas por el gobierno norteamericano.

FL MERCADO DE EURODÓLARES ${ }^{7}$

Los llamados eurodb́lares no son más que depósitos bancarios de monedas distintas a las del país de origen del banco tenedor del depósito. Así por ejemplo, todos los depósitos en cualquier banco inglés que fueran hechos en dólares, francos franceses, marcos alemanes, o en general, en cualquier moneda distinta a la libra esterlina, se considera como un depósito de eurodólares. Igual se puede

${ }^{7}$ Ver Bell (9) y Swoboda (83). 
hablar de eurodólares por depósitos en moneda extranjera en bancos del Japón, Francia, Alemania o cualquier otro país.

El auge de este mercado se experimentó a mediados de la década de los 60 , cuando los mayores intereses europeos comenzaron a atraer fuertes sumas de dólares norteamericanos. La tendencia expansiva se mantuvo, e incluso se fortaleció, debido a las mayores restricciones de salida de capital que se impusieron en los E. U. A., pues dichas restricciones, no hicieron otra cosa, sino, elevar el tipo de interés pagado a los eurodólares, lo que originó un mayor estímulo para la expansión de este tipo de depósitos, que alcanzaron así magnitudes realmente astronómicas, en los primeros años de la década de los 70.

Los usos fundamentales que tienen estos recursos son de corto plazo, para así obtener beneficios por tipos de interés diferenciales, especulaciones monetarias, compra y venta de oro, etc.

La existencia de ese mercado de eurodólares, constituye un factor desestabilizador y de gran peligro para el Sistema Monetario en general, debido a que el mismo puede expandirse con gran rapidez y en magnitudes muy elevadas, introduciendo desequilibrios en la liquidez internacional y, como veremos más adelante en detalle, desajustes de gran importancia en los tipos de cambios flotantes, que en la actualidad (1975) existen, debido a la facilidad que éstos dan para realizar operaciones especulativas de compra-venta de monedas.

E1 proceso de expansión de estos depósitos es el mismo que se aplica en el otorgamiento de créditos de cualquier banca nacional. Así, un banco inglés A, puede otorgar un crédito que es depositado en un banco B de Italia, quien, a su vez, los presta y deposita en el banco $\mathbf{C}$ de Alemania y así sucesivamente. Es decir, un depósito primario de eurodólares, puede dar origen a un proceso multiplicador de los mismos a través de las operaciones crediticias inter-bancarias.

GESTACIÓN DE LA CRISIS ${ }^{8}$

Una vez lograda la reconstrucción de los países devastados por la Segunda Guerra, éstos comenzaron a ganar el terreno perdido en el campo económico. Alemania experimentó uno de los progresos más fantásticos. Ya para fines de la década de los 50, las reservas de estos paises habían crecido considerablemente, sus tenencias de oro también experimentaron un aumento considerable, y durante la primera mitad de los años 60, el bloque del Mercado Común Europeo, llegó

sVer Aliber (2) y Silva (81). 
a ocupar una posición de primera línea en el mundo económico. Ya no era el dólar la divisa utilizada, casi con exclusividad, en las operaciones comerciales internacionales, sino que, algunas monedas europeas, eran solicitadas cada vez con mayor frecuencia, lo que originó el uso, cada vez mayor, de los recursos del Fondo Monetario Internacional a través de los Derechos de Giro.

Tal incremento de demanda de recursos, hizo necesario que los países que luego formarian el llamado Grupo de los Diez ${ }^{9}$, pusieran a disposición del Fondo, un monto de $\$ 6.000$ millones para empréstito.

En 1961, debido al persistente superávit de la balanza de pagos en Cuenta Corriente de la Alemania Federal, superávit que por varios años había traspasado los $\$ 1.500$ millones, se desató una especulación contra el marco que culminó en una revaluación, la que aun cuando pequeña, marcó el inicio de lo que diez años después iba a desencadenar la devaluación del dólar.

\section{LA DEVALUACIÓN DE LA IIBRA ESTERLINA ${ }^{10}$}

Si bien el dólar era la moneda de reserva por excelencia, debido a su convertibilidad en oro, la libra también tenía la categoría de moneda "internacional", pero su importancia era considerablemente menor que la del dólar, por no ser convertible en oro. Sin embargo, la posición de Inglaterra como líder del "Commonwealth", permitió que su moneda tuviera esa categoria de moneda de reserva. Sin embargo, al igual que E. U. A., la Gran Bretaña padeció déficits en su balanza de pagos de magnitudes cada vez mayores.

El déficit comercial de la balanza de pagos era muy elevado, llegando para 1964 a los $\$ 1.453$ millones, debido a que los precios internos británicos eran mayores que en el exterior, a la vez que aquellos aumentaban más rápidamente que estos últimos. En otras palabras, la libra estaba sobrevaluada.

La situación, por otra parte, se vio agravada por el flujo neto de capitales al exterior, en magnitudes cada vez mayores, llegando éstos, para 1966 , a los $\$ 1.588$ millones.

Por razones de tipo político y de compromisos financieros internacionales, el gobierno británico se negó a devaluar su moneda para corregir esta situación, y, en cambio, acudió a los préstamos interna-

${ }^{\circ} \mathrm{El}$ Grupo de los Diez está formado por Alemania Federal, Bélgica, Canadá, E.U.A., Francia, Gran Bretaña, Italia, Japón, los Países Bajos y Suecia.

${ }^{10}$ Ver Aliber (2), Grubel (33) y Pernaut (66). 
cionales, con el fin de subsanar el drenaje constante de sus 'reservas internacionales.

La situación se tornó intolerable a fines de 1967, cuando prácticamente las reservas de ese país y su solvencia en el mercado internacional se habian esfumado, por lo que no quedó otra alternativa que devaluar la libra en un $14,3 \%$ con respecto al dólar.

EL PROBLEMA DE LA LIQUidez Y LA CREACIÓN CENTRAL DE RESERVAS

En el año 1967 sucedió, además de la devaluación de la libra, otro hecho de importancia en el Sistema, como fue el acuerdo a que se llegó en la reunión del F. M. I. en Río de Janeiro, para la creación de un activo de reserva internacional por parte del Fondo, que se denominó "Derecho Especial de Giro" (D. E. G.), una moneda internacional, creada por un organismo central, como es el F. M. I. Más adelante se discutirá detenidamente lo referente a esta nueva moneda.

Lo trascendente de dicha acción, es la creación centralizada de un instrumento monetario, que podría ser la base sobre la cual se fundamente el nuevo Sistema Monetario Internacional, resultado de las críticas y proposiciones que habían sido formuladas por varios economistas. Uno de estos fue el mismo Keynes, quien ya para la fecha del tratado de Bretton Woods, vela la conveniencia de la creación de una moneda internacional centralizada e independiente de cualquier nación.

En efecto, una de las críticas que se hizo al Sistema Monetario de Bretton Woods, fue que el volumen de liquidez internacional, dependía de la creación de déficits cada vez mayores en la balanza de pagos de los E. U. A., situación ésta por demás inestable, pues en ese país, privarían siempre sus intereses internos sobre los de las demás naciones y así, si en un momento dado, los Estados Unidos vieran la necesidad de corregir dicho déficit, podrían tomar las acciones necesarias, dejando en segundo plano los aspectos de requerimientos de liquidez, en detrimento de los otros países. Inversamente, los E. U. A. podrían inundar de dólares a otras naciones, como de hecho ha sucedido, creando liquidez en exceso.

Por estas razones, un equipo de economistas ha propuesto la abolición del dólar como moneda internacional, e, igualmente, eliminar el oro como elemento principal del Sistema, debido a la inelasticidad de su producción $y$, por tanto, a su incapacidad de aumentar o disminuir la liquidez internacional, con la rapidez necesaria. 
Uno de estos economistas es Robert Triffin, quien ya a principios de la década de los 60, propuso una modificación del Sistema.

Grosso modo, el plan Triffin (85), (87), (89), (90), propone que todos los países miembros del F. M. I. depositen en éste un mínimo del $20 \%$ de sus reservas en divisas (normalmente dólares o libras esterlinas), con lo que formarían un fondo, que serviría para emitir una moneda internacional central que se le llamaría "bancor", y la cual gozaría de aceptación generalizada en todos los países miembros del Fondo. El F. M. I. podría invertir parte de estos recursos en el mercado, y los intereses o beneficios percibidos de dichas inversiones se distribuirían entre las cuentas de los diferentes países, de acuerdo al aporte de cada uno de ellos.

Eventualmente, los países irían depositando cada vez mayores proporciones de sus reservas de divisas, e incluso, de oro, en el F. M. I., hasta que se lograra que, prácticamente, las reservas de cualquier país estuviesen formadas por oro o "bancors", teniendo estos últimos una paridad fija respecto al oro y por tanto, paridad que no sería afectada por ninguna fluctuación en el tipo de cambio de ninguna moneda.

Después de estudios detenidos, las autoridades del F. M. I. decidirían cuál sería la tasa de crecimiento anual de las reservas internacionales, y cualquier aumento propuesto por el Fondo por encima o por debajo de ese porcentaje prefijado, debería ser previamente aprobado por $\mathrm{X} \%$ de los votos del Fondo (por ejemplo, $80 \%$ o $90 \%$ ).

Cualquier país que requiriera de un préstamo para corregir ciertos problemas internos, podría solicitarlo al F. M. I., institución que también serviría de "Cámara de Compensación", para las relaciones internacionales, de tal forma, que todas las exportaciones de bienes y servicios, por ejemplo, se acreditarían como una expansión en el depósito de "bancors" del país exportador, y las importaciones de bienes y servicios, como una reducción de dicho depósito, comprometiéndose todos los países a aceptar esos cargos y abonos en sus. cuentas respectivas.

Las críticas de inoperabilidad del sistema se basaban, en que losdirigentes de los diferentes países, estarían difícilmente dispuestos a permitir que fuera un organismo internacional quien dispusiera de la soberanía en materia de creación de liquidez. Por otra parte, la aplicabilidad de este sistema exigiría la existencia de una integración económica y política a nivel internacional, que en el momento actuaI no se ha logrado. Con todo, buena parte de las ideas expresadas en este plan, han servido para la estructuración de los planes de reforma que en la actualidad se estudian (Ver págs. 84 y ss.). ${ }^{11}$

${ }^{11}$ Para mayores detalles sobre el Plan Triffin ver Altman (3), Grubel (33), (34) y Yeager (92). 
LOS DERECHOS ESPECIALES DE GIRO ${ }^{12}$

Con la creación de los D. E. G., el Fondo Monetario Internacional, dio un primer paso para la creación de las reservas centralizadas, que permitirian la expansión de la liquidez internacional.

Se acordó, que cualquier país podría hacer uso de los D. E. G., para resolver un problema en su balanza de pagos y aumentar sus reservas internacionales, sin ser necesaria la consulta y aprobación previa por parte del Fondo.

No fue sino hasta el 1 de enero de 1970, cuando se distribuyó la primera emisión de los D. E. G. por un monto de 3.400 millones; un año después, se emitieron 3.000 millones más, y el primero de enero de 1972 se hizo una tercera emisión similar. El total emitido y localizado para fines de 1974 era por tanto de, aproximadamente, 9.400 millones de D. E. G.

El valor inicialmente asignado a cada D. E. G. fue el equivalente a 1/35 de onza troy de oro. Es decir, que al principio equivalía a un dólar. Esta paridad respecto al dólar, ha fluctuado en los últimos años, como consecuencia de las devaluaciones de esta divisa.

Los D. E. G. serían distribuidos entre los países miembros del F. M. I. en igual proporción a la cuota de éstos en el momento de la emisión, y su uso, sería correlativo a las necesidades de reservas de cualquier país. Así, si un país desea obtener una determinada divisa a través del uso de D. E. G., se lo participa al F. M. I., quien designaría el país que va a suministrar la divisa. El suministrador de la divisa, quien recibirá a cambio D. E. G., debe estar solvente y con una balanza de pagos fuerte, no pudiendo negarse a recibir los D. E. G. Esta obligación última se cumple siempre que los balances de D. E. G. que tiene el país suministrador, no excedan del $300 \%$ de su asignación total. El país que suministra la divisa, podrá contabilizar los D. E. G. recibidos, como parte de sus reservas internacionales.

Por su parte, el país prestatario tiene derecho a usar su asignación en forma libre hasta un $70 \%$ de la misma. Es decir, el promedio diario de tenencia de D.E. G. en un período de 5 años, debería ser, por lo menos, el $30 \%$ de la asignación total de D. E. G. en ese período. Si la misma fuera menor a ese porcentaje, el país estaría en la obligación de restituir los mismos en D. E. G. o en oro.

${ }^{12}$ Ver Fleming (23), Gold (31), Habermeier (35), Hirsch (39) y Polak (67). 
Una de las críticas que se han hecho a los D. E. G., es que los mismos fueron distribuidos de acuerdo al porcentaje de la cuota de cada país en el F. M. I. Esto implica que, los países más ricos y por tanto con mayores cuotas, -quienes a su vez son los que tendrían menor necesidad relativa de liquidez internacional-, son los que de hecho reciben la mayor parte de los D. E. G., mientras que los países en vías de desarrollo, que son los que en principio padecen de escasez de reservas más intensas y crónicas, debido a sus constantes déficits en las balanzas de pagos, son los que obtienen una menor participación en el reparto.

LAS DEMANDAS DE ORO A E. U. A. LA POSICIÓN DE FRANCIA

Las ingentes masas de dólares que fluyeran a Europa durante los primeros 20 años de vida del Sistema, habían alcanzado niveles sumamente elevados, mientras que las reservas de oro de los E. U. A. disminuían constantemente. Estas tendencias divergentes preocupaban, cada vez más, a los países receptores de dólares, quienes dudaban de la capacidad de los E. U. A. de convertir éstos en oro.

Por otra parte, esos mismos países sentían crecientes preferencias por mantener sus reservas en oro, en vez de atesorar la sobreabundante divisa norteamericana. Francia era uno de los líderes de este movimiento, pues, en la segunda mitad de la década de los 60 , reclamó a los E. U. A. la conversión de una cantidad bastante elevada de dólares por oro, mientras que otros países, como Alemania, Bélgica, etc., sólo convirtieron pequeñas sumas, pues sabían que el exigirles a los E. U. A. la conversión de la mayoría de los dólares que poseían, sería el derrumbamiento de todo el Sistema, ya que este último país no disponía del oro suficiente para hacer frente a tales demandas. En otras palabras, por un acuerdo tácito, la mayoría de los países europeos no exigieron la conversión, pues sabían que de hecho el dólar era inconvertible.

Francia, sin embargo, tomó la posición líder en favor del oro. El economista Jacques Rueff proponía el retorno al "patrón-oro" para asegurar la tendencia automática al equilibrio de las balanzas de pagos de todos los países. Esto se lograría mediante transferencias de este metal o de monedas equivalentes, desde los países deficitarios, a los que disfrutaban de superavits en sus balanzas de pagos. Así se originarían fluctuaciones en las ofertas internas de dinero y, la consiguiente, modificación en los precios internos, de tal modo que, en los países con superavits se operarían aumentos de precios. De 
esta forma se estimularian las importaciones y desestimularian las exportaciones, tendencias que a la larga corregirían la situación de superávit. Lo contrario sucedería en los países deficitarios.

En principio, proponía Rueff (73), (74), un aumento del $100 \%$ en el precio del oro, para así incrementar las reservas en igual proporción, a la vez que se estimularía la producción de ese metal.

Por acuerdos previos, los E. U. A. e Inglaterra se comprometerían a dedicar sus reservas, duplicadas ya de valor, a convertir en oro los dólares y libras esterlinas que los otros países pudieran tener.

Si estos dos países no tuviesen suficiente oro, aun después de ser revaluado, para hacer frente a las demandas de conversión de sus monedas, otros países podrían ofrecerles préstamos a largo plazo, por un monto igual al valor nominal de oro que se necesitase para realizar la conversión.

Una de las críticas más severas hecha a esta propuesta es la de que la flexibilidad en la creación de liquidez internacional, para adaptarse a las necesidades de esta liquidez, resultaba aún menor que bajo el sistema basado en los acuerdos de Bretton Woods, pues dicho aumento dependería, o bien de los aumentos en la inelástica producción del oro, o bien de las fluctuaciones en el precio o valoración del metal, que en muchos casos está influenciado por factores muy diversos y fuera del control de las autoridades monetarias.

Por otra parte, la aplicabilidad de un sistema de "patrón-oro" en un mundo tan complejo es casi utópico. ${ }^{13}$

EL PREÁMBULO DE LA CRISIS ${ }^{14}$

El período 1968-1970 fue de gran agitación. El franco francés fue devaluado en agosto de 1969, como consecuencia de los aumentos de precios internos que se originaron a raíz de un aumento general de salarios del $15 \%$ en 1968. Este hecho le restaba poder de competencia a los productos franceses en el mercado internacional, por lo que una devaluación del franco era recomendable, a fin de estimular las exportaciones.

Por su parte, el marco alemán (D. M.) se revaluó en 1969, como consecuencia de una especulación desatada contra esa moneda, al perfilarse el triunfo de los social-demócratas en las elecciones de ese año.

${ }^{12}$ Para mayor información ver De Gaulle (18), Rueff (72), (75).

"Ver Aliber (2). 
El proceso fue eminentemente político. Los demócratas cristianos se oponían a una revaluación, pues el encarecimiento de las exportaciones alemanas afectaría a las empresas de ese país, reduciendo sus beneficios. Por el contrario, los social-demócratas, respaldaban a las masas obreras que demandaban mayores ingresos reales y menores precios. Esto se podría conseguir a través de una revaluación del D. M., pues, en esa forma, se estimularían las importaciones, induciendo a una reducción de los precios internos, para competir con los productos importados, reducción de precios que no es otra cosa que un aumento en los ingresos reales de los trabajadores. Al ganar los social-demócratas, las factibilidades de revaluación eran altas, lo que llevó a los especuladores a adquirir D. M. en espera de la revaluación. Frente a la gran demanda de marcos, el gobierno decidió hacer flotar esa moneda y días más tarde, fijó de nuevo la paridad, pero a un nivel más alto que antes. Es decir, se revaluó el marco.

Por su parte, Ganadá decidió dejar flotar su moneda debido a que los Estados Unidos, -país al cual estaban íntimamente atados los canadienses-, experimentaba una inflación elevada. Con la flotación del dólar canadiense, éste se revaluó respecto al dólar americano, hecho que beneficiaba al Canadá, pues de esa forma se abarataban las importaciones, cada vez más costosas, procedentes de los E. U. A.

LA CRISIS.

1971, PRIMERA DEVALUACIóN DEL DÓLAR ${ }^{15}$

El año 1971, marcó el inicio del fin del sistema implantado en Bretton Woods 27 años atrás. Hasta ese año el déficit de la balanza de pagos norteamericana había crecido constantemente. El superávit en Cuenta Corriente, que había compensado en algo el enorme déficit en Guenta Capital, también desapareció, dando lugar, por primera vez en muchos años, a un déficit en esta Cuenta, a consecuencia de los precios cada vez mayores de los productos norteamericanos. Por otra parte, los cuantiosos gastos militares en el exterior, agravaban el problema. Los países europeos y Japón, estaban recibiendo cada vez mayores cantidades de dólares que no deseaban, lo cual, aunado al deseo norteamericano de corregir su condición precaria en la balanza de pagos, dio origen a los sucesos ocurridos entre mayo y el 15 de agosto de 1971.

Los países tenedores de dólares quisieron presionar nuevamente a

${ }^{15}$ Ver Ossola (65), Roosa (71) y Segal (78). 
los EE. UU. a resolver sus problemas de balanza de pagos, exigiéndoles la convertibilidad de parte de sus dólares en oro, pero todos ellos sabian que esto no era suficiente. Las importaciones de la inflación norteamericana eran cada vez mayores, a la vez que, los superavits de sus balanzas de pagos eran muy elevados, por lo que se hacía evidente que una revaluación ayudaría mucho a resolver los problemas.

Ante estas posibilidades cada vez mayores de revaluación, los especuladores intensificaron su campaña contra el dólar. Los países productores de petróleo del Medio Oriente comenzaron a cambiar parte de sus dólares por francos, marcos, yenes y otras monedas, en espera de sus revaluaciones. Igualmente, las compañías transnacionales, no vacilaron en transferir sumas de consideración a sus filiales en los países europeos y en Japón, para así adquirir las monedas de los mismos. Finalmente, otros especuladores utilizando eurodólares, obtenidos a través de empréstitos a corto plazo, pudieron comprar gran cantidad de estas monedas fuertes. Ante esta situación, algunos países como Alemania y Holanda dejaron que sus monedas flotasen, mientras que otros como Suiza, revaluaron las mismas.

Esto, sin embargo, no frenó los movimientos especulativos que siguieron intensificándose, por lo que el flujo de dólares a los países europeos y Japón creciera a ritmos sumamente altos.

Ante la reticencia de estos países a revaluar sus monedas, a pesar de la astronómica demanda que de ellas se estaba haciendo, y ante el peligro de que dichos países exigieran la convertibilidad en oro, de parte de los dólares que ingresaban a sus arcas, el gobierno norteamericano decidió declarar la inconvertibilidad del dólar, así como imponer un recargo en los impuestos de importación del $10 \%$. Estas acciones anunciadas el 15 de agosto de 1971, habian sido tomadas con el fin de proteger a las ya débiles reservas de oro de los EE. UU., a la vez que fomentar un mecanismo de presión sobre los países europeos para que éstos revaluaran sus monedas. Mientras no lo hicieran, los especuladores seguirían vendiéndoles dólares a cambio de marcos, francos, libras o yenes. Por otra parte, el recargo en el impuesto de importación, encarecía los productos europeos y japoneses en un $10 \%$, por lo que las exportaciones de estos países a los EE. UU. tenderían a disminuir, factor que era el que precisamente, querían evitar los europeos y japoneses, al no revaluar sus monedas.

Es bueno aclarar, sin embargo, que estos eventos del 15 de agosto no fueron causa exclusiva de factores internacionales. La economía norteamericana se encontraba en una fase recesiva, la inflación interna iba en constante aumento y los paros laborales eran cada vez más frecuentes. Todos estos problemas debían ser resueltos a la mayor brevedad posible, pues, entre otras cosas, las elecciones presidenciales 
de 1972 eran cada vez más próximas. La devaluación de facto del dólar, as l como el recargo de impuestos de importación, encarecerían los productos importados, estimulándose así la industria interna.

A partir del 15 de agosto de 1971, los países europeos y Japón comenzaron una serie de negociaciones con los EE. UU. para llegar a un arreglo, e igualmente decidieron dejar flotar sus monedas. Estas comenzaron a lucrarse respecto al dólar, operándose con cierta frecuencia la intervención de los gobiernos de esos países, para mantener las fluctuaciones de sus monedas dentro de ciertos límites. Tal situación culminó con el llamado "Acuerdo Smithsoniano" de Washington, firmado el 18 de diciembre de 1971 entre los países afectados por el conflicto.

EL ACUERDO SMITHSONIANO (18 DE DICIEMBRE DE 1971$)^{10}$

En las reuniones realizadas en los salones del "Smithsonian Institute" de Washington, se acordó redefinir las paridades de las monedas europeas y japonesa respecto al dólar y readaptarse al sistema de paridades fijas. Sin embargo, ahora se permitirian fluctuaciones hacia arriba o hacia abajo, en torno a la paridad fijada, del 2,25\%. Es decir, dos monedas distintas al dólar podrían fluctuar sus paridades entre sí hasta un máximo del $4,5 \%$.

El dólar fue devaluado respecto al oro en un $8 \%$, al pasar el precio oficial de $\$ 35$ a $\$ 38$ la onza troy, mientras que el resto de los países revaluaron sus monedas respecto al dólar, en diversas magnitudes (ver tabla No 2). En general, las monedas de los países en vías de desarrollo del mundo occidental, siguieron al dólar en su movimiento a la baja, ya que éstos están fuertemente ligados a esa divisa.

En el acuerdo Smithsoniano, sin embargo, los Estados Unidos ya no se comprometieron, como lo hicieron en Bretton Woods, a mantener la paridad de su moneda.

Dicho acuerdo, que fue llamado por el entonces presidente de los E. U. A., Richard Nixon, "El acuerdo monetario más importante de la historia", no fue tal, pues si bien trataba de solucionar los problemas existentes para la época, no resolvía las fallas de fondo, del Sistema de Bretton Woods, ya expresadas, ni se trataba de un nuevo sistema monetario internacional más estable y sólido.

${ }^{10}$ Ver Segal (78). 
TABLA $\mathrm{N}^{\circ} 2$

FLUGTUACIÓN PORGENTUAL DE LAS PARIDADES RESPECTO AL DÓlAR ENTRE EL 5 DE MAYO DE 1971 Y EL 18 DE DICIEMBRE DE 1971

\begin{tabular}{lc}
\hline & Fluctuación \\
\hline Yen japonés & 16,88 \\
Franco suizo & 13,90 \\
Marco alemán & 13,58 \\
Chelín austríaco & 11,59 \\
Franco belga & 11,57 \\
Florín holandés & 11,57 \\
Franco francés & 8,57 \\
Libra esterlina & 8,57 \\
Peseta & 8,57 \\
Corona sueca & 7,49 \\
Corona noruega & 7,49 \\
Libra italiana & 7,48 \\
Corona danesa & 7,40 \\
\hline
\end{tabular}

Desde un primer momento se sabía que las crisis vividas podrían reaparecer, como en realidad sucedió pocos meses después.

LA CORTA VIDA DEL ACUERDO SMITHSONIANO

A consecuencia de la devaluación sufrida por el dólar, se esperaba que grandes masas de esta moneda retornarían a los EE. UU., pues las exportaciones de ese país se verían estimuladas, a la vez que los especuladores convertirían sus tenencias de monedas europeas, ahora revaluadas, por dólares para así hacer efectiva las jugosas ganancias de la especulación. Sin embargo, la realidad fue otra, pues un aumento considerable en la liquidez interna norteamericana, -producto de grandes déficits presupuestarios de ese país-, originó la caída de los tipos de interés internos, por lo que, los dólares comenzaron de nuevo a fluir, no hacia los EE. UU., sino por el contrario, hacia Europa y otros países con intereses más elevados.

Ante esta situación, la perspectiva de una nueva crisis del dólar se hacía cada vez mayor, por lo que los gobiernos de Alemania, Japón y otros, impusieron medidas más estrictas de control, para evitar la afluencia excesiva de dólares a sus países y así poder man- 
tener la paridad de cambio dentro de los límites establecidos en Washington, meses atrás. La situación fue controlada hasta junio de 1972, habiéndose vivido en esos seis primeros meses del año, una relativa estabilidad en los mercados de cambio.

Sin embargo, mientras esto sucedía, la Gran Bretaña estaba padeciendo de un proceso inflacionario de precios y salarios, a la vez que el gobierno de ese país iniciaba un programa cle estímulo a la economía mediante políticas monetarias y fiscales. Ello originó que las importaciones se expandieran, como consecuencia de los menores precios externos y del auge económico interno producido por las medidas estimulantes del gobierno.

Esta última circunstancia, hizo que parte del producto que antes se exportaba, fuera dirigido a satisfacer la creciente demanda interna. Como era de esperar, el sólido superávit de la balanza de pagos en Cuenta Corriente que se había logrado en la segunda mitad de 1971, desapareció en el primer trimestre de 1972, cuando se observó un déficit de $\$ 136$ millones. Las reservas internacionales de ese país comenzaron a bajar aceleradamente, lo que estimuló una fuga de capitales de grandes proporciones, en los seis primeros meses de 1972, observándose que al final de junio, el flujo de capitales tuvo un saldo negativo de $\$ 2.026$ millones. Uno de los efectos directos de este flujo fue, el abaratamiento o devaluación natural de la libra, hecho que obligó a las autoridades financieras inglesas a dejar "flotar" esta moneda en el mercado, medida tomada el 25 de junio de 1972. Para fines de ese año la libra se había devaluado respecto del clólar en un 9,6\%.

El flujo de capitales desde los EE. UU. e Inglaterra hacia otros países, hizo que las naciones continentales europeas y Japón, tuvieran que absorber más de $\$ 5.000$ millones a mediados de 1972 .

Debido a la firme decisión de los gobiernos de estos países a mantener las paridades establecidas en Washington, tales entradas de capitales no afectaron dichos tipos de cambios prefijados. Sin embargo, las obligaciones que los EE. UU. contraían con estos países receptores de sus dólares iban en aumento constante, en vez de disminuir, como era de esperarse después del "Acuerdo Smithsoniano". A fines de 1972, estas obligaciones alcanzaban a los $\$ 60.000$ millones, mientras que las reservas monetarias norteamericanas, eran de tan sólo $\$ 13.000$ millones.

Con tan delicada situación entra el año de 1973, año en el que sucederán hechos de gran importancia que hundirán definitivamente el ya moribundo sistema establecido 29 años antes en Bretton Woods.

El primer acontecimiento es un flujo especulativo de dinero de Italia a Suiza, utilizando como medio monetario el dólar.

Este movimiento de capitales afectaba a los dos países en él envuel- 
tos. Suiza no deseaba los recursos que recibia, pues los mismos tendían a empeorar la inflación interna que combatía el gobierno de ese país. Igualmente, Italia deseaba contener la fuga de capitales. La medida tomada por ambos países fue liberar sus monedas de la paridad fija establecida, dejando que las mismas flotaran libremente, para que así la lira se abaratara y el franco suizo se encareciera respecto al dólar. De esta forma, los italianos tendrían que dar más liras por el mismo dólar enviado a Suiza, a la vez que con ese dólar, más caro, sólo se podría comprar una menor cantidad de francos suizos.

Por otra parte, los superavits de las balanzas de pagos europeas y japonesa habían aumentado considerablemente en 1972, por lo que los especuladores vieron la posibilidad de revaluación de estas monedas y devaluación del dólar, medida esta última que era previsible, ya que las esperanzas norteamericanas nacidas del acuerdo de Washington en diciembre de 1971, de reabsorber buena parte de los dólares que se encontraban en el exterior, no se cumplieron, por lo que el déficit de la balanza de pagos de ese país, lejos de reducirse, se incrementó tremendamente.

Fue así como en los primeros días de febrero de 1973, los capitales especulativos fluyeron en magnitudes asombrosas hacia algunos países europeos continentales y hacia Japón, no siendo extrañas las transacciones de venta de $\$ 2.000$ millones por día, a fin de adquirir monedas europeas y japonesa.

La situación se tornó intolerable el 9 de febrero, cuando los mercados de cambio decidieron cerrar sus puertas. Tres días después el dólar fue devaluado en un $10 \%$ respecto al oro y por consiguiente, respecto a los D. E. G., pasando el precio del oro a $\$ 42,22$ la onza troy.

Por su parte, la mayoría de las monedas europeas mantuvieron inalterables sus paridades entre si, dejando que las mismas se revaluaran respecto al dólar en un porcentaje similar al $10 \%$. Japón e Italia por el contrario, dejaron flotar el yen y la lira, con el fin de que éstas se revaluaran aún más respecto al dólar.

Los especuladores, sin embargo, no se conformaron con estas acciones, pues se dudaba que pudiera subsistir un sistema que insistiera en tipos de cambio fijos en torno al dólar, moneda de por sí debilitada, ya que habia sido devaluada 2 veces en 14 meses y sobre la cual ya no había la confianza de otrora. 
LOS TIPOS DE GAMBIO FLOTANTES ${ }^{17}$

Dadas estas expectativas pesimistas, una nueva oleada de dólares especulativos inundaron los mercados europeos, a fin de adquirir sus monedas y esperar a que las mismas se revaluaran. El día jueves 1 de marzo de 1973, por ejemplo, el Bundesbank Alemán compró la cifra record de 2.700 millones de dólares especulativos, para así mantener el tipo de cambio del D. M. dentro de los límites fijados en febrero. Situaciones similares ocurrieron en otros mercados de cambio europeos, razones por las cuales las autoridades monetarias decidieron cerrar los mismos, el día 2 de marzo, hasta nuevo aviso.

Otros especuladores prefirieron acudir a los mercados libres de oro, de Londres y Zurich, para comprar el metal, el cual se encareció altamente, llegando a valorarse cerca de los $\$ 90$ la onza troy, para fines de febrero.

Una vez cerrados los mercados de cambio, las autoridades monetarias europeas veían que la solución más viable era, la de dejar flotar sus monedas; sin embargo, los alemanes se oponían fuertemente a dar este paso aisladamente, pues, podría significar nuevas especulaciones contra el marco, que llevarían la paridad de éste a niveles indeseables, no sólo respecto del dólar, sino también con referencia al franco francés, suizo, o cualquier otra moneda europea.

Ante esta situación, las autoridades alemanas propusieron la tesis de "flotación combinada" de las monedas del Mercado Común. Estas mantendrían una paridad fija entre sf, pero flotarian conjuntamente respecto al dólar. Dicha proposición fue aprobada en la reunión de Bruselas, en la cual se acordó que la paridad entre las monedas europeas podría fluctuar un máximo del $2,1 / 4 \%$ de la paridad nominal.

El nuevo proceso de flotación fue bien acogido por muchos economistas, que opinan, que dicho sistema es el mejor de los adoptables. Bajo un sistema de flotación libre, las balanzas de pagos tienden a equilibrarse, pues, si por ejemplo, existe un superávit en un país determinado, la entrega de divisas que ese país realiza para pagar sus importaciones, es menor que las divisas que recibe de otros palses, en pago de sus exportaciones. En esa forma, la moneda nacional tiende a encarecerse, por la mayor demanda de que es objeto,

${ }^{17}$ Para más detalle ver Bloomfield (10), Congdon (16), Friedman (24) ; (25), Johnstone (42). 
lo que desestimula las exportaciones y estimula las importaciones, corrigiéndose por ello el desbalance existente. Inversamente sucede en caso de déficit.

Lógicamente, esto funcionaría si el proceso de flotación fuera perfectamente claro o "limpio", es decir, si no hubiese la posibilidad de intervención de los gobiernos, para mantener la tasa de cambio dentro de ciertos límites. Esto último es lo que se conoce como flotación "sucia" o intervenida.

Por su parte, uno de los argumentos en contra de la flotación, estriba, en que ese proceso interfiere el comercio internacional ante la incertidumbre de variaciones en las paridades. Sin embargo, el mismo argumento se podría aplicar a los tipos de cambio fijos, tal y como existieron hasta 1973, pues no era inusual, que el valor de una moneda fluctuara violentamente en un momento especifico, afectándose de esta forma el comercio, dada la incertidumbre de futuros cambios. Bajo un sistema de flotación libre, por el contrario, es más factible predecir las tendencias a la baja o al alza en las paridades.

El 19 de marzo de 1973, los mercados de cambio europeos reabrieron sus puertas, poniendo en práctica los acuerdos de Bruselas. Una paz monetaria se vivió por primera vez ese año, a pesar de que las condiciones de incertidumbre prevalecian. La situación se mantuvo estable hasta mayo, en que frente a la persistencia y agravamiento de la inflación norteamericana, los dólares volvieron a fluir hacia Europa, siendo la moneda más demandada, el marco alemán. Esto originó una revaluación del mismo, respecto a las otras monedas europeas, del orden del $5,5 \%$, a pesar de que continuó bajo el acuerdo de la flotación conjunta de los paises del Mercado Común Europeo.

A principios de julio, el dólar se había devaluado aproximadamente en un $15 \%$ promedio, respecto de las monedas europeas. Esto dio origen a que tanto las autoridades monetarias europeas como norteamericanas, decidieran tomar acciones para controlar la situación y mantener los tipos de cambios dentro de límites razonables. Se concluye, pues, que la flotación libre del dólar tuvo una vida efímera.

A partir de mediados de 1973, las autoridades norteamericanas anunciaron que ejercerían intervención efectiva en los mercados, para así mantener la paridad del dólar en los niveles deseados. Igualmente, el 8 de julio se dieron a conocer los resultados de las conversaciones, que las autoridades europeas y norteamericanas sostuvieron en la ciudad de Basilea, Suiza, donde se convino, que los países asistentes intervendrían, conjuntamente, para mantener el "orden" 
en los mercados de cambio. En otras palabras, se convino en un sistema de flotación "sucia" o intervenida.

Una de las decisiones adoptadas en esta reunión fue, la de utilizar los acuerdos de empréstitos "Swap" entre los bancos centrales de dichos países. A través de esos acuerdos, la Reserva Federal podría pedir en préstamo monedas europeas a los bancos centrales de ese continente, para asf vender dichas monedas en el mercado, a cambio de dolares, que serían retirados de la circulación por la Reserva Federal. Con esto, la venta de, por ejemplo, marcos alemanes, tendería a abaratar esa divisa, o por lo menos, a reducir la demanda que de ella harían los especuladores directamente en las taquillas del Bundesbank. Con tal procedimiento, este último no se vería forzado a adquirir mayores cantidades de dólares indeseables, a cambio de marcos, lo cual, acarrearía, además de su encarecimiento respecto al dólar, la expansión del circulante interno, con sus efectos inflacionarios conexos.

Simultáneamente a esta venta de monedas europeas por parte de los E. U. A., los bancos centrales de esos países se comprometieron a comprar dólares, con el fin de no permitir la sobrevaluación de sus monedas respecto de éste.

Los efectos de esta medida se hicieron sentir inmediatamente. Al principio, el dólar se recuperó lentamente, pero durante los tres últimos meses del año, tuvo una recuperación sustancial frente a las monedas europeas, debido a una expansión considerable en las exportaciones norteamericanas, como consecuencia de la subvaluación del dólar después de las dos devaluaciones anteriores, así como a las menores presiones inflacionarias sufridas en los EE. UU., con respecto a los demás países desarrollados.

Esta recuperación del dólar se reafirmó durante la primera mitad de 1974, año en el que se siguió operando bajo el sistema de flotación conjunta de las monedas europeas, y en el que sucedieron acontecimientos de gran trascendencia en la economía mundial, que afectaron directamente las relaciones monetarias internacionales. Fue quizás el aumento de los precios del petróleo lo que mayor impacto y consecuencias tuvo en la economía mundial durante ese año y lo que ha transcurrido de 1975 (junio).

LOS PRECIOS DEL PETRÓLEO Y SUS REPERCUSIONES EN LAS RELACIONES MONETARIAS INTERNACIONALES

A fines de 1973, la Organización de Países Exportadores de Petróleo, O. P. E. P., acordó aumentar los precios de venta del petróleo y 
aquellos utilizados para el cálculo de los beneficios de las compañías transnacionales dedicadas a las operaciones de explotación petrolera en los países productores. Tal hecho originó un aumento en los precios de venta o realización de ese producto y sus derivados, en los mercados internacionales, de aproximadamente un $300 \%$, en comparación con los precios de enero de 1973. Dichos precios se han mantenido, desde esa fecha, hasta los actuales momentos, razon por la cual los países consumidores de petróleo, han visto incrementado el valor de sus importaciones de manera sustancial. Esta es una de las razones, -junto con la del encarecimiento de otros productos de importación dentro de la inflación mundial-, que originaron déficits en las balanzas comerciales de una serie de países, tanto desarrollados como en vías de desarrollo, durante 1974 .

Entre los países desarrollados que presentaron déficits en sus balanzas de pagos, se cuentan los EE. UU., Italia, Inglaterra y Japón, pero una notable excepción de esta regla fue Alemania, donde se experimentaron superavits a pesar del aumento en el valor de sus importaciones, pues éstas fueron compensadas con una exitosa expansión en las exportaciones, lo cual, aunado a una tasa inflacionaria relativamente baja, determinó que la economía alemana fuera una de las más favorecidas y fuertes del mundo durante 1974. Consecuencialmente, durante la primera mitad de ese año, el marco se revaluó respecto del dólar, cambiando el ritmo de fortalecimiento que experimentó la moneda norteamericana, en la segunda mitad del año 1973, a causa de las intervenciones gubernamentales que se hicieron en el mercado internacional de cambios, después de los acuerdos de Basilea en junio de 1973.

Sin embargo, en sentido general, se puede decir, que el dólar norteamericano se revaluó con respecto a la mayoría de las monedas de los países desarrollados, a excepción del D. M., durante los nueve primeros meses del año 1974, ello debido, por una parte, al hecho de que las autoridades financieras de ese país impusieron una política de restricción monetaria interna, por lo que los intereses tendieron al alza, dando origen a un flujo de capitales hacia ese país y por tanto, una mayor demanda de dólares que encareció dicha moneda. Por otra parte, los pafses productores de petróleo estaban obteniendo cuantiosos ingresos, recursos que no podían ser gastados de inmediato dentro de esas economías, pues de hacerse así, las presiones inflacionarias que estas economías sufrirían serían enormes por no tener la capacidad de absorber esos recursos en su totalidad. Así, los gobiernos de dichos países decidieron colocar una buena parte de esos ingresos petroleros en el exterior; esta colocación dio origen a los llamados "Fondos de Petrodólares", que para 1974 alcanzaron la cifra de $\$ 60.000$ millones. Aproximadamente el $18 \%$ de estos "petrodólares", 
fueron invertidos en los EE. UU. mediante la compra de títulos del Gobierno, en acciones de compañías norteamericanas, o simplemente, colocándolos en depósitos de bancos norteamericanos. El consiguiente aumento de la demanda de moneda norteamericana, dio como resultado, una revalorización de la misma.

Incluso el marco alemán, se unió a las demás monedas europeas en su tendencia a la baja respecto al dólar, a fines de la primera mitad de 1974; en parte, debido a la disminución de la confianza sobre el D. M., que se originó, como consecuencia de la quiebra del Hersttat Bank de Alemania, y la divulgación de los tropiezos financieros de otros bancos de esa nación, provenientes de grandes pérdidas sufridas como consecuencia de excesivos préstamos "forward", en un mercado de tasas de cambio flotantes, donde ese tipo de crédito es mucho más riesgoso, que en un mercado donde imperan paridades fijas.

No es sino hasta octubre de 1974, cuando el debilitamiento de las monedas europeas finaliza, y comienza a operarse una recuperación de las mismas respecto al dólar, como consecuencia del agravamiento de la situación económica norteamericana, donde se vivia una inflación de considerable magnitud y donde las características de una recesión tomaban más fuerza día a día, hechos todos que debilitaron la confianza en el dólar, operándose una tendencia al alza, en favor de buena parte de las monedas europeas, tal es el caso del marco alemán, el florín holandés, el franco suizo, el franco francés y otras.

Están ausentes de esta lista, sin embargo, la libra esterlina, la lira italiana y el yen japonés, en las cuales, la recuperación de fines de 1974 no se hizo presente, como consecuencia de los problemas económicos que vivían los países emisores de estas monedas. Por una parte, Inglaterra vivía en estado de recesión desde la segunda mitad de 1973, situación que se agravó con los mayores precios petroleros y con los aumentos de salarios del orden de un 28,5 \% sólo en 1974 .

Japón por su parte sufrió durante ese año, una de las inflaciones más severas (superior al $20 \%$ ), aunada a un constante déficit en su balanza de pagos; fue tan sólo en septiembre de ese año, cuando, por primera vez, se gozó de un superávit de $\$ 100$ millones, gracias a un convenio de ese país con Arabia Saudita, conforme al cual, el gobierno de este último, depositó $\$ 1.000$ millones, en bancos japoneses. Es, precisamente, en el mes de septiembre cuando se notó una cierta recuperación del yen frente al dólar, para luego volver a caer en octubre al nivel de los 300 yenes por dólar, nivel en que se mantuvo hasta fines del año.

Italia por su parte, vivió en 1974 uno de los años más caóticos en su historia económica. La inflación era mayor al $20 \%$, los niveles de desempleo superaban el $14 \%$ y los déficits en su balanza comer- 
cial, eran de gran magnitud, debido, no sólo a los mayores precios del petróleo, sino también, a la alta dependencia exterior de Italia, para el suministro de materias primas y otros bienes, cuyos precios aumentaban en forma acelerada.

Durante los dos primeros meses de 1975, la tendencia de revalorización de algunas monedas europeas ha continuado, destacándose el franco suizo, que se ha revaluado hasta un $22 \%$ sobre el dólar, como consecuencia de movimientos especulativos que se iniciaron a raíz de una fuerte compra de esa moneda por parte de algunos países árabes, que buscaban diversificar sus tenencias monetarias. Esto estimuló a los especuladores, quienes comenzaron a cambiar dólares por francos suizos. Ante tal situación, el gobierno suizo tomó medidas drásticas, para impedir estas especulaciones y con ellas la expansión excesiva de circulante interno, para lo cual estableció un interés negativo de un $10 \%$ trimestral, sobre todos los depósitos en francos suizos de no residentes, que hubiesen sido hechos después del 31 de octubre de 1974.

La declinación del dólar se acentuó aún más, durante los últimos días del mes de febrero de 1975, cuando los países miembros de la O. P. E. P. estudiaron en Viena, la posibilidad de aumentar el precio del petróleo, para compensar las devaluaciones del dólar, en los mercados internacionales. También se discutió la posibilidad, de sustituir el dólar por los D. E. G., como moneda en la cual se establecieran los precios petroleros, para así evitar las necesidades de ajuste de éstos, frente a las fluctuaciones del dólar. A pesar de que no se tomó ninguna de las dos decisiones, -sino que, por el contrario, se decidió seguir usando el dólar como moneda contable y se rebajaron los precios de algunos crudos-, el simple hecho de realizarse las discusiones, indujo cierta desconfianza en la moneda norteamericana, por lo que la misma perdió valor en los mercados internacionales, cotizándose para el 28 de febrero de 1975 a uno de los niveles más bajos conocidos. Para mediados de marzo de 1975, algunos países productores de petróleo del Medio Oriente, -entre ellos Arabia Saudita-, liberaron sus monedas del dólar, ligando las paridades de éstas a los D. E. G., para así protegerse de los vaivenes de la moneda norteamericana en los mercados de cambio internacionales.

Estas tendencias a la baja del dólar han continuado hasta la fecha (junio de 1975), razón -entre otras-, por las que los ministros de O. P. E. P., reunidos en Libreville, Gabón, durante la primera mitad de junio, decidieron ligar los precios del petróleo a los D. E. G.; en lugar del dólar norteamericano, a partir del l de octubre de 1975.

De esta forma, se evitarán las pérdidas que estos países sufren al valorar el petróleo en términos de una moneda que constantemente se devalúa en el mercado internacional. Acciones similares han sido 
tomadas por otras organizaciones y países; tal es el caso de la "I. A. T. A.", donde se decidió utilizar los D. E. G. como la unidad de referencia en que se fijarán las tarifas aéreas internacionales a partir del 1 de abril de 1977; y Egipto, país cuyo gobierno decidió reabrir el Canal de Suez a partir del 5 de junio de 1975 , estimando el monto de las tarifas a ser cobradas a los buques que hicieran uso del canal en términos de D. E. G.

LOS PETRODÓLARES Y SUS INCIDENCIAS EN LA ECONOMÍA MUNDIAL

Como fue dicho previamente, la coyuntura de mayores precios petroleros, permitió a los países productores de petróleo beneficiarse de altos ingresos, durante 1974 y lo que va de 1975, lo cual, sumado a la imposibilidad de estos países, de absorber la totalidad de esos recursos, dio origen a un flujo de capitales de los petroleros a otras naciones, tanto desarrolladas, como en vías de desarrollo. Ha sido este flujo de recursos financieros lo que se ha dado por llamar el "reciclaje de los petrodólares".

Igualmente, los destinos y orientaciones que han tomado estos petrodólares, han estado altamente influenciados por los efectos, que el alza en los precios del petróleo, y el proceso inflacionario mundial, han tenido en las diferentes economías.

Un ejemplo que robustece este hecho, es la creación, a mediados de 1974, del llamado "Servicio Financiero del Petróleo" por parte del F. M. I., a través del cual, algunos países de la O. P. E. P., dieron en préstamo, al expresado organismo, una cantidad aproximada de 3.000 millones de D. E. G., con el fin de crear un fondo de ayuda a los países miembros del F. M. I., que tuvieran dificultad en su balanza de pagos, como consecuencia -se repite- de los mayores precios del petróleo.

Cualquier país miembro del F. M. I. que tenga problemas en su balanza de pagos, como consecuencia de los precios del petróleo, podrá solicitar a aquel organismo, la compra de divisas que le sean necesarias, para amortiguar el impacto negativo de estos déficits. Los países que demuestren que en realidad tienen este tipo de problemas, se les permitirá la compra de esas divisas a un tipo de interés del $6,875 \%$ anual, bajo el compromiso de devolución de dichas divisas, cuando sus problemas de balanza de pagos sean superados.

Los días 15 y 16 de enero de 1975 el Comité Provisional de Gobernadores del Fondo se reunió en Washington, donde se decidió que el Servicio Financiero de Petróleo sería ampliado en 1975, hasta 
un monto de 5.000 millones de D. E. G., y en cumplimiento de la decisión, el Sr. H. J. Wittenveen, Director General del F. M. I., viajó por varios países árabes y Venezuela durante los meses de febrero y marzo de 1975, con el fin de obtener los recursos financieros necesarios para la ampliación del servicio. Otros países han acordado con el F. M. I. otorgar créditos a este último con el fin de engrosar los fondos para el Servicio Financiero del Petróleo. Tal es el caso de Austria, Bélgica, Alemania, Países Bajos, Noruega y Suiza.

TABLA N 83

PRESTAMOS DE LOS PAfSES EXPORTADORES DE PETRóleo AL F. M, I.

PARA LA CREACIÓN DEL SERVICIO FINANGICRO DEL PETRóleo;

PARA AGOSTO DE 1974

\begin{tabular}{lc}
\hline Pais & $\begin{array}{c}\text { Prestamos } \\
\text { Millones de D.E.G. }\end{array}$ \\
\hline Abu Dhabi & 100,00 \\
Canadá & 257,91 \\
Irán & 580,00 \\
Kuwait & 400,00 \\
Omán & 20,00 \\
Arabia Saudita & $1.000,00$ \\
Venezuela & 450,00 \\
Totái & $2.807,91$ \\
\hline
\end{tabular}

FUENTE: Boletín del F. M. I., 26 de agosto de 1974, pág. 257.

Al cierre del ejercicio 1974/1975 del F. M. I., el día 30 de abril de 1975, 38 países, - la mayoría de ellos en vías de desarrollo-, habłan adquirido divisas a través del Servicio Financiero del Petróleo, por un montante de 2.500 millones de D. E. G.

Además de aquellos aportes al F. M. I., los países miembros de la O. P. E. P. facilitaron recursos a países en desarrollo por un monto de $\$ 8.600$ millones, solamente durante el período de enero a septiembre de 1974. Buena parte de estos fondos se canalizaron a través de organismos financieros internacionales, tales como el Banco Mundial, el Banco Interamericano de Desarrollo, el Banco Islámico de Desarrollo y otros. El resto de estas ayudas fueron negociadas directamente entre los paises participantes.

Por otra parte, se estima, que el $30 \%$ de los ingresos excedentes de los países de la O. P. E. P., fueron colocados en el mercado de las euromonedas. Las operaciones de crédito de este mercado aumen- 
taron tremendamente en los primeros meses de 1974, para así financiar los déficits de balanzas de pagos aparecidos como consecuencia del encarecimiento de las importaciones, no sólo de petróleo, sino también de un gran número de productos. Este hecho permitió que los intereses en ese mercado se elevaran, atrayendo de esta forma fuertes sumas de petrodólares. Los créditos otorgados durante los seis primeros meses de 1974 (\$ 19.229 millones), montaron a una cantidad casi igual a los créditos otorgados durante todo el año 1973 (\$22.023 millones).

Sin embargo, la segunda mitad de ese año no fue tan activa en este mercado como la primera, ya que los créditos otorgados se redujeron a tan sólo $\$ 8.056$ millones. La razón de esta reducción se debió, en parte, a la desconfianza que apareció en el mercado durante esos meses, cuando se estimó que la solvencia de los principales países deudores en el mismo, se estaba debilitando como consecuencia de los precios del petróleo, por lo que una buena parte de los suplidores de este mercado, comenzaron a retirar sus depósitos. Los países árabes, sin embargo, continuaron aumentando sus colocaciones en los eurobancos.

\section{EL MERCADO DEL ORO ${ }^{18}$}

Como ya se dijo previamente los precios del oro en el mercado libre y en el mercado oficial fueron bastante similares como consecuencia del "pool" del oro que firmaron algunos de los principales países europeos y Estados Unidos a fines de 1960. No es sino hasta 1968, cuando ese convenio se terminó y se acordó separar ambos mercados, dejando la valorización del metal en el mercado libre, al juego de la oferta y la demanda, y manteniéndose el precio oficial de éste al nivel estipulado en Bretton Woods, de $\$ 35$ la onza troy.

A partir de esa fecha, el precio del mercado libre, muestra una tendencia de ascenso bastante prudente, no siendo sino hasta 1971, cuando la primera crisis del Sistema Monetario Internacional originó un robustecimiento en la confianza de este metal, dada la característica de estabilidad de su valor, y por tanto, se desencadenó un aumento en su demanda, hasta llevar su precio al nivel de los $\$ 60$ la onza troy, el que se mantuvo durante todo lo que restó de 1972.

Al iniciarse 1973, sobreviene la segunda gran crisis del Sistema Monetario con la devaluación del dólar en un $10 \%$, y con la deter-

\footnotetext{
${ }^{18}$ Ver Machlup (51), Shannon (79), Triffin (88) .
} 
minación de las monedas europeas de establecer una paridad fija respecto al dólar, pero a un nivel más alto que el fijado en el Acuerdo Smithsoniano de diciembre de 1971. Este hecho originó, que los especuladores dudaran de la estabilidad del dólar y de la posibilidad de vida de un sistema de paridades fijas, respecto a una moneda débil, como lo era ahora la unidad monetaria norteamericana, razón por la cual decidieron deshacerse del dólar, a cambio de monedas europeas y de oro. El precio libre de este metal tendió así al alza, hasta colocarse en el rango de los \$90 la onza troy, precio que no perduró por mucho tiempo, ya que pocos días después, las especulaciones monetarias tomaron grandes magnitudes, obligando a las autoridades de los países europeos a cerrar sus respectivos mercados de cambio el día 2 de marzo de 1973. Ante la imposibilidad de adquirir estas monedas fuertes, los especuladores dirigieron sus fondos hacia los mercados del oro, llegando el valor del metal cerca de los $\$ 130$ la onza troy. Sin embargo, al reabrirse los mercados de cambio europeos a mediados de marzo, la "fiebre" del oro disminuyó, pues ya había la posibilidad de adquirir monedas fuertes, que para la fecha se encontraban flotando conjuntamente con respecto al dólar. Esta contracción en la demanda del metal hizo que su precio bajase a niveles cercanos a los $\$ 100$ la onza, donde se mantuvo hasta las últimas semanas de ese año.

A mediados de noviembre, suceden hechos de importancia: por una parte, se decide eliminar una serie de "acuerdos" sobre el oro que habian establecido en 1968 Estados Unidos y algunos países europeos, con el fin de restringir el acceso de los organismos oficiales al mercado libre del fino metal.

Por otra parte, fueron estos los días en que se produjo el embargo petrolero del Medio Oriente y la posterior decisión de aumento conjunto de los precios del crudo y sus derivados por parte de la O.P.E.P., hechos que ensombrecieron las perspectivas económicas y financieras de los países consumidores, entre los que se encontraban las naciones de la Comunidad Europea, Estados Unidos y Japón. La confianza en las monedas de estos países decayó, factor que originó un incremento aún mayor en la demanda de oro, llevando su precio en forma paulatina hasta los niveles "record" de casi $\$ 180$ la onza troy, durante los primeros meses de 1974. A partir de ese momento, este precio comenzó a descender lentamente, pues, a consecuencia de los mayores intereses existentes en el mercado, era más rentable colocar los fondos en éste, que mantenerlos en oro. Esta situación imperó hasta mediados de junio, cuando se divulgaron las recomendaciones del Comité de los 20 para la reforma del Sistema Monetario (ver págs. 84 y ss.), que incluiría, entre otras, las de restarle importancia al papel del oro en el nuevo Sistema, hecho que introdujo 
incertidumbre en el mercado, originándose un aumento en las ventas de oro, con la consiguiente caída de su precio, hasta situarse en un mínimo de $\$ 136,63$ la onza, durante los comienzos de junio de 1974.

A partir de ese momento, se empezó a observar una recuperación en el precio del metal, como consecuencia de las agitaciones políticas internacionales en Chipre y Norteamérica, recuperación que se hace presente casi ininterrumpidamente, excepto durante el mes de septiembre, cuando se nota cierta contracción.

Ante la proximidad del 19 de enero de 1975 , fecha en la cual se volvería a permitir a los norteamericanos la tenencia del oro, los mercados europeos son testigos de fuertes compras durante el mes de noviembre de 1974, con el fin de atesorar el metal y volcarlo luego sobre el mercado norteamericano, donde se estimaba existiría una demanda de grandes proporciones tan pronto entrara el año 1975. Ante estas perspectivas y temerosas las autoridades norteamericanas de una fuga masiva de dólares hacia el exterior, como consecuencia de las compras de oro, se anunció a fines de 1974 que el 6 de enero de 1975 el Tesoro de ese pais subastaría 2 millones de onzas troy. Igualmente, iniciaron una campaña publicitaria, tratando de desanimar a los norteamericanos en realizar compras masivas del metal.

Estas últimas medidas dieron excelentes resultados, pues las demandas de oro por parte de los norteamericanos fueron muy pequeñas, lo que origino una vertiginosa caída en el precio del metal, que pasó de casi $\$ 200$ la onza a fines de noviembre de 1974 , a $\$ 170$ en los primeros días de enero de 1975.

Sin embargo, a partir del 6 de enero, el oro comenzó a mostrar una nueva recuperación, como consecuencia de las mayores compras por parte de los europeos, y quizá de los árabes, para protegerse de las precarias condiciones de inflación y recesión que aún viven los países más desarrollados.

Desde esa fecha, no se han notado mayores cambios en el precio del metal. Tan sólo a mediados de febrero, éste aumentó en el mercado de Londres ante el anuncio de ciertos bancos centrales de algunos países del Mercado Común Europeo de la posibilidad de revaluación de sus reservas de oro, y de la realización de transacciones de oro entre éstos. Al no hacerse realidad estos anuncios, el precio comenzó a declinar en forma paulatina. A mediados de abril de 1975, frente a una recuperación momentánea del dólar, el precio del oro se contrajo a uno de los niveles más bajos de los últimos meses ( $\$ 164$ la onza), volviéndose a recuperar casi en forma inmediata. A mediados de mayo se opera una nueva recuperación $(\$ 174$ la onza), como consecuencia de un nuevo debilitamiento del dólar en el mercado internacional. 
Una nueva tendencia a la baja del oro se comenzó a operar casi en forma inmediata, hasta que a principios de junio éste se cotizó a $\$ 163$ la onza, nivel donde se ha mantenido hasta el presente (mediados de junio de 1975). Esta nueva baja fue consecuencia del anuncio hecho por las autoridades norteamericanas de la próxima subasta de 500.000 onzas de oro a ser realizada el 3 de junio de 1975 .

\section{LA REFORMA DEL SISTEMA ${ }^{10}$ INTRODUCGIÓN}

Como se ha dicho ya, han sido múltiples las proposiciones de reforma del Sistema Monetario establecido en Bretton Woods, siendo Keynes quien proféticamente emitió las primeras críticas cuando el Sistema aún estaba en periodo de gestación.

Años después, fue Triffin, quien expuso un plan de reforma sistemático a principios de los años 60 , y del cual se han extraído una serie de ideas y principios sobre los que se fundamentaron algunos criterios y modificaciones recomendadas actualmente (ver págs. 62-3).

Otros economistas han defendido puntos de vista diametralmente opuestos, tal es el caso de Jacques Rueff, defensor del retorno al "patrón-oro" y Milton Friedman, quien recomienda el sistema de tipo de cambio flotante, para así asegurar los ajustes automáticos de las balanzas de pagos, y, de esta forma, resolver el problema de ausencia de mecanismos de ajuste, de que padecía el Sistema de Bretton Woods.

Son múltiples los economistas que han ofrecido otras alternativas de reforma, tal es el caso de Zelotas (94), Harrod (36) y (38), Aliber (1), Machlup (50), Harry G. Johnson (40), y muchos otros, pero que, por razón de brevedad, no las describiremos detalladamente; sólo nos concentraremos al estudio preliminar de la reforma que el llamado "Comité de los 20" presentó a mediados de 1974, después de más de dos años de discusiones.

REFORMA PROPUESTA POR EL COMITĹ DE LOS 20

A mediados de 1972, se eligió el "Comité de la Junta de Gobernadores para la Reforma del Sistema Monetario Internacional y Ma-

${ }^{10}$ Ver F.M.I. (28), Grubel (34), Kafka (43) y Silva (81). 
terias Afines" (Comité de los 20), que estaba constituido por representantes de 20 países tanto desarrollados como en vías de desarrollo: Alemania, Argentina, Australia, Bélgica, Brasil, Canadá, EE. UU., Etiopía, Francia, Gran Bretaña, India, Indonesia, Israel, Italia, Japón, Marruecos, México, Países Bajos Suecia y Zaire, con el fin de estudiar las posibles reformas al Sistema.

Durante la reunión anual de septiembre de 1973 del F. M. I. en Nairobi, Kenya, dicho Comité presentó su primer esbozo de la reforma, pero dado lo complejo de la materia, se le dio una extensión hasta julio de 1974, para presentar el informe final.

La formulación de esta reforma no es tarea fácil, ya que no sólo se refiere a la reforma monetaria del Sistema, sino que entran en juego otros aspectos tan importantes, como los del comercio internacional, los ajustes de las balanzas de pagos y la disponibilidad de liquidez necesaria para los países en desarrollo, lo cual complica tremendamente la tarea de lograr un nuevo sistema que satisfaga los intereses internos, y en muchos casos contrapuestos, de las 125 naciones miembros del F.M.I.

\section{LA REFORMA 20}

A mediados de 1974 el Comité de los 20 presentó el documento de "Bosquejo de la Reforma". En el mismo se establece que, dada la complejidad del problema, no se puede aspirar a realizar una reforma a plazo inmediato, sino que, por el contrario, es necesario ir introduciendo modificaciones y mejoras al Sistema en forma paulatina. Sin embargo, el Comité, en dicho bosquejo, estableció las bases sobre las cuales podría fundamentarse el nuevo sistema.

Analizando la cuestión se tiene que, en primer lugar, el F.M.I. pasaría a ser una organización de gran poder de decisión internacional, obligándose los países miembros a acatar las directrices que dicha Institución emitiera con el fin de hacer operativo el sistema. En otras palabras, la operatividad del nuevo sistema descansaria en el F.M.I.

${ }^{20}$ Ver Comité de los 20 (13), Silva (81). 


\section{CARACTERÍSTICAS PRINCIPALES DEL SISTEMA}

Las principales características de la reforma serían, entre otras:

1) Un proceso eficaz de ajuste de las balanzas de pagos.

2) Tipos de cambio estables, pero ajustables.

3) Control de flujos de capitales desequilibradores.

4) Existencia de convertibilidad.

5) Los D.E.G. como principal activo de Reserva, disminuyendo las funciones del oro y de otras divisas internacionales.

6) Fomento del flujo de recursos reales a los países en desarrollo.

Todo país debería tomar medidas de ajuste sin demora para evitar desequilibrios sostenidos en sus balanzas de pagos. Igualmente, debería mantener sus reservas internacionales dentro de ciertos límites, que no fueran nocivos al volumen de liquidez internacional.

Sin embargo, estas medidas de ajuste - sobre todo, las que realizaran los países desarrollados-, no deberían afectar a los países en vías de desarrollo, a través de la reducción en la asistencia financiera y material que los primeros presten a los segundos, ni tampoco, a través del empeoramiento de los términos de intercambio.

El Fondo, por intermedio de su Directorio Ejecutivo, determinaría, después de una evaluación detenida y con el auxilio de ciertos indicadores, cuando un país debería tomar acciones de ajuste en su balanza de pagos con el fin de corregir sus desequilibrios, quedando a criterio del país afectado, decidir qué medidas deberían tomarse o reforzarse, siempre que éstas estuvieran previamente aprobadas por el F.M.I. 
Los tipos de cambio entre las monedas serían estables, habiendo la posibilidad de ajustes y de modificaciones dentro de ciertos límites. En otras palabras, los gobiernos se comprometerían a mantener sus respectivas paridades, permitiendo ciertas fluctuaciones dentro de límites máximos y mínimos, tratándose de establecer estos últimos, con un criterio mucho más amplio y operativo que los establecidos en Bretton Woods y en el Acuerdo Smithsoniano.

En algunos casos, cuando las autoridades del Fondo así lo juzgaran necesario, se le podría permitir a determinado país la flotación de su moneda, siempre y cuando, esta flotación, no vaya en contra de los intereses internacionales.

Tanto el país cuya moneda se permita flotar, así como todas las demás naciones que intervinieran en actividades con esa moneda, se deberían someter a las condiciones impuestas por el Fondo, reservándose este último, el derecho de suprimir el permiso de flotación, cuando lo juzgara conveniente.

CONTROL SOBRE EL FLUJO DE GAPITALES DESEQUILIBRADORES

Los países podrían implantar controles sobre la existencia de tipos de cambio indeseados y otros efectos contrarios, siempre y cuando estos controles no afectaran directamente a los paises en vias de desarrollo. Se trataría, de que los controles establecidos no afecten las inversiones privadas en los países en desarrollo, e igualmente, los frenos legales o institucionales a la entrada de capitales a un país desarrollado, no deberían aplicarse a los países menos favorecidos, para así permitir a estos últimos el acceso a los mercados financieros de los palses industrializados.

Igualmente, las medidas de control de entrada o salida de capitales, deberian tomarse de mutuo acuerdo con el Fondo, a fin de evitar efectos negativos en las relaciones económicas internacionales, a la vez que pudiera lograr la mayor efectividad en las medidas mediante la comunicación y cooperación centralizada entre los paises, a través del Fondo. 


\section{EXISTENCIA DE CONVERTIBILIDAD}

Todos los países tendrían obligaciones simétricas con referencia a las reservas, incluso aquellos países que sean emisores de monedas de reserva, e igualmente, todas las naciones se someterían a las normas impuestas por el Fondo a fin de evitar el aumento excesivo de los saldos formados por monedas de reserva.

El Fondo mantendría un control sobre cada país, para asegurar que el aumento de sus tenencias de monedas de reserva, fuera cónsona con la expansión de las operaciones comerciales internacionales y también para evitar que un país aumentara sus reservas hasta niveles desproporcionados con sus volúmenes de importaciones.

Este último punto iría en perjuicio directo de los países exportadores de petróleo, quienes a los precios actuales de ese producto, han podido atesorar reservas de gran magnitud, llegando las mismas a niveles que en algunos casos, son equivalente al valor de las importaciones que ese país realizaría en cinco años o más.

Las anteriores medidas persiguen el objetivo de evitar que las reservas aumentaran a niveles indeseables en cualquier país. A los efectos de evitar que ningún país emisor de moneda de reserva se excediese en la emisión de la misma - tal como fue el caso de los EE. UU. durante la vigencia del Sistema de Bretton Woods-, se estableció que esas naciones tendrían la obligación de liquidar con activos de reserva, las demandas de conversión, que, sobre su moneda, realizara cualquier organismo oficial de otro país.

Esa conversión podría realizarse en oro, o en cualquier otro activo de reserva, incluyendo los D. E. G., por lo que el Fondo tendría una participación activa en estas operaciones de conversión, suministrando D. E. G. al país emisor de la moneda de reserva, para que éste pudiera hacer frente a las demandas de conversión que, de sus monedas, pudiera realizar otra nación.

Igualmente, no se estableció cuáles volúmenes o porcentajes de las tenencias de moneda de reserva que cada país tuviera, podría ser. convertida por el país tenedor de las mismas. Una posibilidad podría ser la de que el Fondo estableciera límites máximos de monedas de reserva que cualquier país pudiera mantener, permitiéndose y obligándose a cada país solicitar la conversión de todo excedente sobre ese límite, a la nación emisora.

Por otra parte, todo país emisor de monedas de reserva, podría recomendar a las otras naciones, que se limiten en el atesoramiento 
de su moneda en forma de reservas oficiales, o en la conversión que de la misma hagan estos últimos países. Tales recomendaciones deberian ser respetadas.

Igualmente, la composición de las reservas, si bien sería competencia de cada país, no podría ser modificada sin la previa consulta al Fondo.

Por último, dada la importancia que han jugado los recursos de eurodólares en los movimientos desestabilizadores del Sistema Monetario Internacional en los últimos años, a través de movimientos especulativos en esos fondos, el Comité de los 20 recomendó, que ningún país pudiera aumentar sus colocaciones en monedas de reservas fuera del país emisor de las mismas, sin previa consulta y apro bación del Fondo, quien establecería límites máximos para este tipo de colocaciones.

LOS D. E. G. COMO PRINCIPAL ACTIVO DE RESERVA

Un aspecto de gran significación en el bosquejo de reforma, es la importancia que se da a los D. E. G. como pilares sobre los que descansaria buena parte del Sistema Monetario. En efecto, los D. E. G. serían el activo de reserva más importante en el Sistema, en detrimento del oro y de otras monedas de reserva, sirviendo esta unidad monetaria internacional, de unidad de valor en la que se expresarían las paridades de todas las otras monedas.

Con esta disposición, se le daría al Fondo Monetario Internacional, la capacidad de controlar la expansión o contracción de la liquidez internacional, de acuerdo a las necesidades que de ellas se tuviera; necesidades estas, que serían establecidas en el Fondo, de acuerdo al comportamiento de ciertos indicadores que se establecerían después de un estudio a ser realizado por los expertos del Fondo. Igualmente, como arriba se enunció, los tenedores de D. E. G., podrían gozar de intereses, para que así fuera atractivo adquirir este tipo de moneda.

Sin embargo, uno de los problemas que se le presentó al Fondo fue, la creación de un mecanismo de determinación de valor de transacción para los D. E. G. A tal efecto, se decidió que a partir del 1 de julio de 1974, el valor de esta moneda internacional se estimaría siguiendo el método de la llamada "cesta uniforme". Según este método, se seleccionaron aquellos países cuyas exportaciones en 
el período 1968-1972 representaron el $1 \%$, o más, de las exportaciones mundiales totales. Sólo 16 países cumplían este requisito.

Se formaría una "cesta" compuesta por las monedas de estos países, de acuerdo a la participación de cada uno de ellos en el comercio internacional en tal forma, que el valor en dólares de las monedas incluidas sumaran, el día 30 de junio de $1974, \$ 1,20635$, que era el valor de un D.E. G., después de las dos devaluaciones del dólar, y que por tanto era el que existía para la fecha.

A partir del 1 de julio de 1974, el valor de un D. E. G. se determinaría diariamente, valorando las monedas incluidas en la cesta, de acuerdo al tipo de cambio que las mismas tuvieran en el mercado de Londres.

Un ejemplo aclara el proceso: Se estableció que la participación porcentual y la de las monedas en la cesta sería:

TABLA N $\mathbf{N}^{9} 4$

\begin{tabular}{|c|c|c|c|}
\hline \multirow[b]{2}{*}{ Estados Unidos } & \multirow{2}{*}{$\frac{\%}{33,0}$} & \multicolumn{2}{|c|}{$\begin{array}{l}\text { Cantidad de } \\
\text { esas monedas }\end{array}$} \\
\hline & & US\$ & 0,40 \\
\hline Alemania Federal & 12,5 & $\mathrm{DM}$ & 0,38 \\
\hline Reino Unido & 9,0 & $£$ & 0,045 \\
\hline Francia & 7,5 & FF & 0,44 \\
\hline Japón & 7,5 & Y & 26,00 \\
\hline Canadá & 6,0 & $\$$ & 0,071 \\
\hline Italia & 6,0 & $\mathrm{~L}$ & 47,00 \\
\hline Países Bajos & 4,5 & DIf. & 0,14 \\
\hline Bélgica & 3,5 & $\mathbf{F}$ & 1,60 \\
\hline Suecia & 2,5 & $\mathbf{K r}$ & 0,13 \\
\hline Australia & 1,5 & $A \$$ & 0,012 \\
\hline Dinamarca & 1,5 & $\mathrm{Kr}$ & 0,11 \\
\hline Noruega & 1,5 & Kr. & 0,099 \\
\hline España & 1,5 & $P_{\text {ta. }}$ & 1,1 \\
\hline Austria & 1,0 & $S$ & 0,22 \\
\hline Africa del Sur & 1,0 & $\mathbf{R}$ & 0,0082 \\
\hline & TOTAL & & \\
\hline
\end{tabular}

Fuente: Boletín del F. M.I., 15 de julio de 1974, pág. 213.

Si por ejemplo se desea saber el valor en US $\$$ de un D. E. G. el día 2 de julio de 1974 se tiene: 
TABLA NQ 5

VALORACIÓN DEL D.E.G. DEL FONDO MONETARIO INTERNACIONAL, 2 DE JULIO DE 1974

\begin{tabular}{|c|c|c|c|}
\hline $\begin{array}{l}\text { Monedas } \\
\text { (1) }\end{array}$ & $\begin{array}{c}\text { Componentes } \\
\text { monelarios } \\
\text { (2) }\end{array}$ & $\begin{array}{c}\text { Tipos } \\
\text { de cambio } \\
2 \text { de julio } \\
\text { de } 1974 \\
\text { (3) }\end{array}$ & $\begin{array}{c}(2 / 3) \\
\text { Equivalente } \\
\text { en dólares } \\
\text { de E.UA. } \\
\text { (4) }\end{array}$ \\
\hline Dólar de Estados Unidos & 0,4000 & 1,00000 & 0,100000 \\
\hline Marco alemán & 0,3800 & 2,55750 & 0,148583 \\
\hline Libra esterlina & 0,0450 & 2,38800 & 0,107460 \\
\hline Franco francés & 0,4400 & 4,81350 & 0,091410 \\
\hline Yen japonés & 26,0000 & 285,90000 & 0,090941 \\
\hline Dólar canadiense & 0,0710 & 1,02850 & 0,073024 \\
\hline Lira italiana & 47,0000 & 646,50000 & 0,072699 \\
\hline Florín holandes & 0,1400 & 2,66350 & 0,052562 \\
\hline Franco belga & 1,6000 & 38,10000 & 0,041995 \\
\hline Corona sueca & 0,1300 & 4,37500 & 0,029714 \\
\hline Dólar australiano & 0,0120 & 0,67227 & 0,017850 \\
\hline Corona danesa & 0,1100 & 5,98100 & 0,018392 \\
\hline Corona noruega & 0,0990 & 5,44350 & 0,018187 \\
\hline Peseta española & 1,1000 & 57,27000 & 0,019207 \\
\hline Chelín austríaco & 0,2200 & 18,25500 & 0,012051 \\
\hline \multirow[t]{2}{*}{ Rand sudafricano } & 0,0082 & 0,66669 & 0,012300 \\
\hline & D.E.G. de U & $\begin{array}{l}\text { D.E.G.I } \\
\text { 1,00 D.E.G. }\end{array}$ & $\begin{array}{l}1,206375 \\
0,828930\end{array}$ \\
\hline
\end{tabular}

Cotizados en relación con las unidades monetarias por dólar de E.U.A., excepto para la libra esterlina y el dólar canadiense, que se cotizan como dólares de E.U.A. por unidad de moneda, según la práctica del mercado.

FUENTE: Boletín del F.M. I., 15 de julio de 1974, pág. 214.

Con referencia al oro, el nuevo sistema trataría de restarle importancia como activo de reserva, no habiéndose encontrado para la fecha de la presentación del "bosquejo", cuál política se debería seguir a tal efecto. Sin embargo, parece antagónico que dadas estas ideas de reducir la función del oro en el Sistema Monetario, los presidentes de Francia y E. U. A. convinieron, a fines de 1974, establecer el derecho de revaluar sus tenencias de oro, valoradas hasta esa fecha al precio oficial de $\$ 42,22$ la onza troy, a los precios del mercado libre, es decir, cuadruplicar el precio de ese metal, de tal forma, que sus golpeadas reservas internacionales a consecuencia de los precios petroleros, se fortalecieran con esta medida. 
Entre los días 9 al 12 de junio de 1975 el Grupo de los 10 sostuvo una reunión en París, donde se discutió lo referente al papel que jugaría el oro en el nuevo Sistema. Sin embargo, los resultados de esta reunión estuvieron lejos de ser los deseables, ya que las posiciones defendidas por algunos países como EE. UU. y Francia son irreconciliables. EE. UU. por una parte defiende la desmonetización del metal, mientras que Francia propone que el F. M. I. devuelva el oro a los países miembros, quienes lo valorarían al precio del mercado libre, engrosando de esta forma sus reservas.

Lo único que fue decidido en la reunión de París fue que el Fondo debería vender parte de sus tenencias de oro en el mercado libre, para así beneficiar a los países en vías de desarrollo.

\section{EL FOMENTO DEL FLUJO DE REGURSOS REALES \\ A LOS PAÍSES EN DESARROLLO ${ }^{21}$}

Es característico de los países en vías de desarrollo, por una parte, el ser exportadores de productos básicos, cuyos precios y volúmenes de compra están fundamentalmente controlados por los países compradores, excepto raras excepciones, como es, ahora, el caso del petróleo; y, por otra parte, el ser países altamente dependientes del exterior, en cuanto al suministro, no sólo de materias primas y bienes de capital que no poseen, sino también de bienes de consumo masivo, no producidos internamente.

Estas circunstancias determinan que dichos países sean altamente afectados por las fluctuaciones en los tipos de cambio de las monedas de los países industrialmente más avanzados, particularmente por los cambios en la paridad del dólar, pues es, en esta moneda, en la que se establecen los precios de gran parte de los productos que exportan los países en vías de desarrollo. Por otro lado, las revaluaciones de las monedas europeas y japonesa, así como las presiones inflacionarias mundiales, encarecen sus importaciones. De aquí se desprende que dichos paises presentan con gran frecuencia déficits en sus balanzas de pagos, y por ende, reducción en sus reservas internacionales, las que, en muchos casos, llegan prácticamente a desaparecer. Por ello, son estos países los más urgidos de liquidez internacional para poder realizar sus programas de desarrollo.

La reforma del Sistema Monetario Internacional debe tener como uno de sus objetivos centrales, la promoción del desarrollo econó-

\footnotetext{
${ }^{21}$ Ver C.E.M.L.A. (12), Cooper (15), Kafka (44)
} 
mico, a través de la creación de mecanismos que permitan el flujo de recursos reales, hacia los países en desarrollo.

Además de las medidas de control que se impondrían a los países industrializados, -cuando éstos tomaran acciones de reajustes de sus balanzas de pagos-, para que las mismas no afectaran a los paises en desarrollo (ver punto a), se ha recomendado que para la estimación de los requerimientos de liquidez internacional por parte del Fondo, se tome más en consideración las posiciones de las balanzas de pagos de estos últimos países.

Igualmente, habría un vínculo entre la asistencia para el desarrollo y la asignación de los D. E. G., asignación que podría realizarse siguiendo cualesquiera de los dos patrones siguientes:

1) Que se le asignen los D. E. G. a cada país de acuerdo a sus necesidades de liquidez internacional, permitiéndose de esta forma, que los países en vías de desarrollo reciban una asignación mucho mayor a la que les correspondería si la misma se realizara de acuerdo con la cuantía de las cuotas en el Fondo.

2) Que se establecieran las necesidades globales de liquidez de los países en desarrollo, y de acuerdo a éstas, se le asignaran los D. E. G. necesarios a las organizaciones internacionales y regionales de financiación del desarrollo. Ellas a su vez, se encargarían de distribuir o suministrar los D. E. G. a los países en desarrollo, de acuerdo a sus planes y necesidades.

La segunda alternativa es, quizás, la que acarrearía menor número de problemas entre los países industrializados, ya que, de adoptarse la primera, las naciones desarrolladas podrían argüir que al estar una parte sustancial de D. E. G. en poder de los países en desarrollo, la estabilidad, y, en general, la confianza que sobre ese activo de reserva se tuviera, tenderían a ser menores.

Por otra parte, no son sólo aspectos de tipo monetario los que hay que solucionar. Es necesario que se fomenten las exportaciones diversificadas de los países en vías de desarrollo, a la vez que se diversifiquen las industrias de tales países, para lo cual se hace necesario, que el flujo de capitales hacia éstos se haga mayor mediante medidas que eliminen, o si no suavicen, las trabas legales que impidan a estas naciones el acceso a los mercados financieros mundiales.

Igualmente, se hace necesario el mayor dinamismo en el otorgamiento de préstamos a esos países, como asimismo el aumento de asistencia oficial internacional al desarrollo. 


\section{COMENTARIOS $\mathrm{Y}$ SUGERENCLAS}

En principio, puede decirse, que el sistema propuesto por el Comité de los 20, aporta un conjunto de soluciones a los problemas actuales, tanto en el aspecto monetario como de comercialización y desarrollo, habiéndose logrado el establecimiento de un conjunto de normas y principios, que estructuran un sistema monetario internacional viable y de actual aplicabilidad.

Sin embargo, consideramos, que en el perfodo transitorio que actualmente vivimos $-\mathrm{y}$ durante el cual se está tratando de realizar la adaptación al nuevo sistema-, es conveniente anotar ciertas críticas y comentarios sobre el sistema propuesto, tratando de aportar algunas ideas sobre posibles acciones a tomar con el fin de solucionar dichos problemas.

LA POSICIÓN DEL FONDO MONETARIO INTERNACIONAL EN EL NUEVO SISTEMA

Uno de los puntos más positivos en el Sistema del Comité de los 20 es, la investidura que se le daría al Fondo Monetario Internacional como organismo de gran poder de decisión a nivel internacional, pues, de esta forma, se aseguraria un control eficaz, excluyendo así todo interés nacionalista o aislado.

Sin embargo, es importante hacer notar, que al ser tomadas las decisiones en este organismo en base a un proceso de votación, proporcional al tamaño de la cuota de los palses miembros, el mismo está dominado por un pequeño grupo de poderosos países, quienes, de no modificarse el sistema de toma de decisiones a los efectos del nuevo sistema, mantendrían el dominio sobre este último, y podrían bloquear la aprobación, por parte del Fondo, de cualquier acción internacional que los afectara negativamente, aun cuando ésta fuera en beneficio de la mayorfa de los países.

A tal efecto, sería conveniente que el Consejo Permanente y Representativo -grupo que se encargará de supervisar la gestión del sistema monetario-, estuviera formado por un conjunto de personas que representaran, equitativamente, los intereses de todos los países miembros del Fondo; y, que las decisiones que dicho Consejo tomase, 
fueran realizadas en base a un conjunto de indicadores automáticos, o en caso de la inaplicabiliclad de este sistema, en base al mecanismo de votación, pero donde el poder de voto de cada miembro del Consejo contara por igual.

AJUSTES DE LAS BALANZAS DE PAGOS

Una de las tareas más arduas a realizarse en el Fondo es, la de establecer los indicadores objetivos y automáticos que determinen la necesidad de ajustes en las balanzas de pagos de los países. La dificultad de esta tarea estriba, en que pueden ser múltiples y de diversa indole, las causas por las que un país puede tener problemas de déficit o superávit en su balanza de pagos, lo que hace, que las medidas de ajuste aplicables o recomendables para un país, puedan estar contraindicadas, para otra nación, con un déficit similar al del primero. Es por tanto recomendable, que estos indicadores sean utilizados principalmente como un mecanismo que alerte en forma inmediata a las autoridades del Fondo, sobre la presencia de desajustes de la balanza de pagos de un país; y en una segunda etapa, discutir directamente con el país afectado, las causas de su problema y los efectos que puedan tener los diferentes mecanismos de ajuste. Por último, se decidiría, conjuntamente, qué medidas han de ser adoptadas a fin de solucionar el problema existente, de tal forma, que las mismas afectasen en la menor medida posible los otros aspectos económicos de esa nación.

CONTROL SOBRE EL VOLUMEN DE RESERVAS DE CADA PAÍS

Como ya fue expresado, una de las recomendaciones del Comité de los 20 fue, la que el Fondo Monetario Internacional, debería mantener controles sobre la tenencia de reserva, por parte de los diferentes países (ver págs. 88-9), a fin de evitar desproporciones de éstas, con sus necesidades de liquidez internacional.

Este propósito no es fácil de alcanzar en todos los casos, pues, por regla general, los países que logran atesorar reservas en exceso, son aquellos que, o bien juegan un papel económico de importancia en la economía mundial $-y$ por tanto tienen gran poder de decisión individual-, o bien son países que, aun cuando débiles individual- 
mente, han logrado agruparse formando organizaciones defensoras de sus productos en el mercado internacional. Un clásico ejemplo de este último caso es la O. P. E. P., cuyos miembros han llegado a atesorar ingentes reservas en tan sólo un año, debido a la elevación de los precios de petróleo. Como es fácil suponer, estos países han logrado posiciones de gran poder, y que hoy han llegado a constituirse en potencias financieras mundiales, no estarían dispuestos a desprenderse fácilmente de su excedente de reservas, pues las mismas constituyen, una fuente de ingresos de importancia, a la vez que tales recursos son un fondo que podría servir para financiar los programas futuros de desarrollo en dichos países.

Se hace necesario por lo tanto, idear planes de acción o programas por parte del Fondo Monetario Internacional, que aseguren, en la mayor medida posible, el control del crecimiento de reservas, y a la vez que, este control afecte, en el menor grado posible a los países, para que estos estén dispuestos a acatarlos, tarea que como es de suponer, no es fácil de lograr.

EL CONTROL DE LAS ACCIONES ESPECULATIVAS

Como es conocido, uno de los factores desestabilizadores de mayor importancia en el sistema monetario actual son los movimientos especulativos de monedas en escala internacional, los cuales, si bien buena parte de los mismos son realizados por gobiernos de algunos países, o compañías transnacionales, también los especuladores individuales juegan un papel de importancia en estas actividades, siéndoles posible, a estos últimos, realizar sus operaciones debido a la oferta de créditos a corto plazo, en mercados como el de eurodólares.

Bajo el nuevo sistema se piensa controlar el crecimiento de este tipo de mercados, limitando el volumen de divisas que cualquier país podría colocar en el exterior, en otro país distinto al emisor de la divisa. Esto, de lograrse, podría restringir considerablemente el crecimiento del mercado de eurodólares, pero, sin embargo, es posible, que no frene o elimine sustancialmente las acciones especulativas internacionales. A tal efecto, podría considerarse la posibilidad de establecerse un control de cambios automático en los mercados de cambio, de los países cuyas monedas sean objeto de este tipo de acciones. Tal mecanismo podría funcionar de la siguiente forma: Dadas las paridades monetarias estables, pero ajustables, se establecerían límites máximos y mínimos en torno a dichas paridades, dentro de las cuales, habría mercados de cambio libres, de tal forma que si, 
por ejemplo, cualquier moneda tiende a revalorizarse, debido al aumento de su demanda, al llegarse a un tipo de cambio igual a su límite máximo, las autoridades monetarias del país emisor, dejarian de vender libremente su moneda y exigirían que los compradores de la misma, por encima de una cantidad razonable, justifiquen su operación de compra, demostrando que la cantidad obtenida sería utilizada en alguna operación específica como inversiones, importaciones u otras. Igualmente, este país podría imponer otras medidas, tales como intereses negativos sobre depósitos a corto plazo de extranjeros en los bancos de la nación afectada.

Un proceso similar, pero a la inversa, podría aplicarse en aquellos países cuyas monedas han alcanzado los límites mínimos, estableciéndose en éstos, medidas de control de cambios para evitar las fugas de capitales.

víNCULOS DEL NUEVo SISTEMA CON LOS PROGRAMAS DE DESARROLLO

Dado que entre los objetivos del nuevo sistema se encuentra el de estimular el desarrollo de los países más necesitados, sería aconsejable que los organismos de fomento internacionales tales como el Banco Mundial, el Banco Interamericano de Desarrollo y otros, intervengan, o al menos, sean consultados, en todo lo concerniente a las acciones y decisiones que afectan a ese grupo de países. Así lo manifestó el llamado Grupo de los 24, formado por representantes de países del tercer mundo y que tiene como objetivo la defensa de los derechos de éstos.

Quizás una forma de relacionar el Consejo Permanente y Representativo del F. M. I. con estos otros organismos de fomento sea a través de la incorporación a dicho Consejo de una serie de representantes de estas últimas instituciones en calidad de consejeros en materia de desarrollo, permitiéndoseles a los mismos el derecho a voz en todas las gestiones realizadas por el Consejo, y además, derecho de voto en la toma de decisiones que afecten directamente a los países en vías de desarrollo.

Otro aspecto que debe tomarse en consideración dentro del nuevo sistema, es el del otorgamiento de ayudas y préstamos más amplios y con grado de exigencias y garantías menos severas que aquellas aplicables a los países más desarrollados. El Grupo de los veinticuatro ha sugerido, entre otras, el que se cree un servicio por medio del cual se otorguen préstamos por períodos mayores y con intereses prefe- 
renciales a los países en vías de desarrollo, para resolver problemas internos, tales como los de balanza de pagos y otros.

Los anteriores comentarios pueden considerarse que tienen validez en la fase de transición en que actualmente atraviesa el mundo de las finanzas, al pasar del viejo Sistema de Bretton Woods al nuevo y complejo sistema que recién comienza a nacer.

\section{BIBLIOGRAFIA}

I. Aliber, Robert Z.: National Preferences and the scope for International monetary reform, Princeton University, International Finance Section, Dep. of Economics, Princeton, N. J., 1973.

2. - The International Money Game, Basic Books Inc., 1973.

3. Altman, Oscar: Professor Triffin on International Liquidity and the Role of the Fund, Staff Papers, Vol. VIII, mayo 1961.

4. - International Liquidity and the Balance of Payments, Staff Papers, Vol. XII, nov. 1965.

5. Angel, James: The Reorganization of the International Monetary System, en World Monetary Reform: Plans and Issues, H. G. Grubel, Editor, Stan. ford University Press, 1965.

6. Audrey, Henry: Behind the Veil of International Money, Princeton University, International Finance Section, Dep. of Economics, Princeton, N. J., 1969 .

7. Balogh, Thomas: International Reserves and Liquidity, en World Monetary Reform: Plans and Issues, Grubel, Editor, Stanford University Press, 1965.

8. B.C.V.: Economía y Finanzas Internacionales, Caracas, 1974, Varios.

9. Bell, Geoffrey: The Euro-Dollar Market and the International Financial System, John Wiley \& Sons, New York, Toronto, 1973.

10. Bloomfield, Arthur I.: Living with Floating Exchange Rates, The Wharton Quarterly, Winter 1973.

11. - : The Historical Setting, en European Monetary Unification and its meaning for the United States; Krause y Salant, Editores, The Brookings Institution, 1973.

12. C.E.M.L.A.: América Latina y la Liquidez Internacional, CEMLA, México, 1970.

13. Comité para la Reforma de Sistema Monetario Internacional y Cuestiones Afines (Comite de los 20): Reforma Monetaria Internacional. Documentos del Comité de los 20, F.M.I., Washington, 1974.

14. Cohen, B. J.: Balance of Payments policy, Penguin Books, 1970.

15. Cooper, Richard N.: The Relevance of International Liquidity to Developed Countries, Yale University, Economic Growth Center, New Haven, 1968.

16. Congdon, Tim: Floating Rates, International Currency Review, agosto 1974.

17. De Vries, Tom: An Agenda for Monetary Reform, Princeton University, Dep. of Economics, Princeton, N. J., 1972.

18. de Gaulle, Charles: Return to the Gold Standard, en The International Monetary System: Problems and Proposals, Officer y Willett, Editores, Prentice Hall Inc., 1969.

19. Despres, Emile: Proposal for an International Dollar Standard, en The In- 
ternational Monetary System: Problems and Proposals, Officer y Willett, Editores, Prentice Hall Inc., 1969.

20. Eimzig, Paul: Foreign Exchange Crises, MacMillan \& Co. Ltd., Edimburgo, 1970.

21. Eltis, Walter: Do Flexible Exchange Rates Work in Practice?, International Currency Review, mayo-junio 1974.

22. Fleming, Marcus: The International Monetary Fund: Its Form and Functions, Washington, 1964.

29. — : The S.D.R.: Some Problems and Possibilities, Staff Papers, Vol. XVIII, marzo 1971.

24. Friedman, Milton: Frec Market Determination of Exchange Rate, en The International Monetary System: Problems and Proposals, Officer y Willett, Editores, Prentice Hall Inc., 1969.

25. ——: The Balance of Payments, Free Versus Exchange Rates, A.E.T. for PPR, Washington, 1967.

26. Friedman, Irving S.: Inflation, A World wide Disaster, Anchor Books, 1975.

27. - - The International Monetary System: Part I Mechanism and Operation, Staff Papers, vol. X, julio 1963.

28. F.M.I.: Reforma del Sistema Monetario Internacional, informe de los Directores Ejecutivos a la Junta de Gobernadores, Washington, 1972.

29. —_: Informes Anuales 1964-1974, Washington, D.C.

30. - : Survey, varios.

31. Gold, Joseph: Special Drawing Rights. The Role of Language, FMI, Washington, 1971.

32. Grubel, Herbert G.: Estados Unidos cono Banquero Mundial, CEMLA, 1965.

33. - The International Monetary System, Penguin Books, 1969.

34. __ : World Monetary Reform: Plans and Issues, Stanford University Press, 1965.

35. Habermeier, Walter: Operations and Transactions in SDR's. The First Basic Period, IMF, Washington, 1973.

36. Harrord, Sir Roy: A Plan for Increasing Liquidity: A Critique, en World Monetary Reform. Plans and Issues, Grubel, Iditor, Stanford University Press, 1968.

37. —-: The Dollar, MacMillan, N. Y., 1953.

38. - - Liquidity, en World Monetary Reform: Plans and Issues, Grubel, Editor, Stanford University Press, 1963.

39. Hirsch, Fred; S.D.R.'s and the Working of the Gold Standard, Staff Papers, vol. XVIII, julio 1971.

10. Johnson, Harry G.: International Liquidity: Problems and Plans, en World Monetary Reform: Plans and Issues, Grubel, Editor, Stanford University Press, 1965.

41. - : Narrowing the Exchange Rate Banks, en European Monelary Unification and its Meaning for the United States, Krause y Salant, Editores, The Brookings Institution, 1973.

42. Johnstone, Robert: Experiencia con Tipos de Cambios Flotantes, Boletín Mensual de CEMLA, mayo 1974.

43. Kafka, Alexander: The IMF Second Coming, Princeton University, Dep. of Economics, Princeton, N. J., 1972.

44. -_- International Liquidily: its present relevance to less developed countries, American Economic Association, 1968.

45. Kindleberger, Charles P.: Los déficils de balanza de pagos y la demanda internacional de liquidez, CEMLA, 1965. 
46. Klopstock, Fred H.: El mercado monetario internacional: Estructura, amplitud $e$ instrumentos, CEMLA 1965.

47. Krause, Lawrence R.: Sequel to Bretton Woods, The Brookings Institution, Washington, 1971.

48. Losada, Benito Raúl: Sintesis Monetaria, Ediciones Banco Central de Venezuela, Colección XX Aniversario, Caracas, 1971.

49. Machado Gómez, Alfredo: Crisis y Recuperacion. La Economía Monetaria Venezolana entre 1961 y 1968, Ediciones Banco Central de Venezuela, Colección XXX Aniversario, Caracas, 1972.

50. Machlup, Fritz: Reform of the International Monetary System, en World Monetary Reform: Plans and Issues, Grubel, Editor, Stanford University Press, 1965.

51. - The Book Value of Monetary Gold, Princeton University, Dep. of Economics, Princeton, N. J., 1971.

52. — : The adjustment problem and the balance of payments policy of the United States, en The International Monetary System: Problems and Proposals, Officer y Willett, Editores, Prentice Hall Inc., 1969.

53. Machlup, Fritz y otros: Planes de Reforma del Sistema Monetario Internacional, CEMLA, 1965.

54. Maisel, Sherman J.: Managing the Dollar, W. W. Norton \& Co. Inc., New York, 1973.

55. Makin, John H.: Capital flows and exchange-rate flexibility in the post Bret. ton Woods era, Princeton University, International Finance Section, Dep. of Economics, Princeton, N. J., 1974.

56. Marshall, Jorge: ¿Qué pasa con el Sistema Monetario Internacional?, artículo inédito, 1974.

57. Maza Zavala, D. F.: El Problema de la Liquidez Internacional, Revista de Economía y Ciencias Sociales, número extraordinario, enero-noviembre 1966.

58. - - La internacionalización del Bolivar y la Liquidez Internacional, Ediciones Cuatricentenario de Caracas, Caracas, 1967.

59. McKimmon, Ronald: A new tripartite Agreement or a limping dollar Standard?, Princeton University, International Finance Section, Dep. of Eco. nomics, Princeton, N. J., 1974.

60. Meade, James E.: The future of International Payments, en World Monetary Reform: Plans and Issues, Grubel, Editor, Stanford University Press, 1965.

61. - : The various forms of exchange-rate, flexibility, en The International Monetary System: Problems and Proposals, Officer y Willett, Editores, Prentice Hall Inc., 1969.

62. Monroe, Wilbur F.: International Monetary Reconstruction, Lexington Books, Toronto, 1974.

63. Mundell, Robert: The Dollar and the Policy Mix 1971, Princeton University, International Finance Section, Dep. of Economics, Princeton, N. J., 1971.

64. Mundell, R. A., y Swoboda, A., Editores: Monetary Problems of the International Economy, The University of Chicago Press, Chicago, 1969.

65. Ossola, Reinaldo: Toward New Monetary Relationships, University of Princeton, International Finance Section, Dep. of Economics, Princeton, N. J., 1971.

66. Pernaut, Manuel: La Devaluación de la Libra Esterlina 1967, Colección Samán, No 12, UCAB, Caracas, 1967.

67. Polak, J. J.: Some Reflections on the Nature of Special Drawing Rights, FMI, Washington, 1971.

68. Roosa, Robert V.: Assuring the free world's liquidity, en World Monetary Reform: Plans and Issues, Grubel, Editor, Stanford University Press, 1965. 
69. - - : Benefits and responsibilities of the U.S. as world banker, en The International Monetary System: Problems and Proposals, Officer y Willett, Editores, Prentice Hall Inc., 1969.

70. - Monetary Reform for the World Economy, Harper \& Row, N. X., 1965.

71. Roosa, Robert y otros: The Dollar Crisis, The Banker, sept. 1971.

72. Rueff, Jacques: Balance of Payments; Proposals for the Resolution on the most Pressing World Economic Problems of our times, MacMillan, N. Y., 1967.

73. - - Gold Exchange standard: A danger to the rwest, en World Monetary Reform: Plans and Issues, Grubel, Editor, Stanford University Press, 1965.

74. - Increase in the price of gold, en The International Monetary System: Problems and Proposals, Officer y Willett, Editores, Prentice Hall Inc., 1969.

75. - : The monetary sin of the wost, The MacMillan Co., Londres, 1972.

76. Salant, William A.: The Future of the dollar reserve system, en The International Monetary System: Problems and Proposals, Officer y Willett, - Edi: tores, Prèntice Hail Inc., 1363.

77. Schmitt, Bernard: New Proposals for World Monetary Reform, Lditions Castella, Albeuve, Suiza, 1973.

78. Segal, Ronald: The decline and fall of the american dollar, Bantam Books, 1974 .

79. Shannon, Ian: Gold and the American Balance of Payments, H. Regnery, Chicago, 1966.

80. Silva, Carlos Rafael: Concepto, Composición y Función de las Reservas Monetarias Internacionales. Análisis Pormenorizado del Caso Venezolano, Edi. ciones del Cuatricentenario de Caracas, Caracas, 1965.

81. - - El Sistema Monetario Internacional, su reciente evolución y perspectivas, B.C.V., Caracas, 1974.

82. Snider, Delbert A.: International Monetary Relations, Random House Inc., Nerv York, 1966.

83. Swoboda, Alexander: The Euro-Dollar Market. An Interpretation, Princeton University, International Finance Section, Dep. of Economics, Princeton, N. J., 1968.

84. Tew, Brian: Cooperación monctaria internacional, Editorial Labor, Barcelona, 1970.

85. Triffin, Robert: After the gold exchange standard?, en World Monetary Reform: Plans and Issues, Grubel, Editor, Stanford University Press, 1965.

86. - : The Balance of Payments and the Foreign Investment Position of the United States, Princeton University, International Finance Section, Dep. of Economics, Princeton, N. J., 1966.

87. - : The Evolution of the International Monetary System: Historical Reappraisal and Future Perspectives, Princeton University, International Finance Section, Dep. of Economics, Princeton, N. J., 1964.

88. - - Gold and the Dollar Crisis: The Future of Convertibility, Yale University Press, 1961.

89. - : Neither Gold nor the dollar, en The International Monetary System: Problems and Proposals, Officer y Willett, Editores, Prentice Hall Inc, 1969.

90. — : Our International Monelary System: Yesterday, Today and Tomorrow, Random House, N. Y., 1968.

91. - - El Caos Monetario, Fondo de Cultura Económica, México, 1961.

92. Yeager, Leland B.: The Triffin Plan: Diagnosis, Remedy and Alternatives, en World Monetary Reform: Plans and Issues, Grubel, Editor, Stanford University Press, 1965.

93. - - Unilateral action on international monetary policy, en The Interna- 
ESTUDYOS INTERNAGIONAEES

tional Monetary System: Problems and Proposals, Officer and Willett, Editores, Prentice Hall Inc., 1969.

94. Zolotas, Xenophon: Toward a reinforced gold exchange standard, en World Monetary Reform: Plans and Issues, Grubel, Editor, Stanford University Press, 1965. 